DEPARTMENT OF ECONOMICS

Working Paper Series

Political Awareness and Microtargeting of Voters in Electoral Competition

Burkhard Schipper

University of California, Davis

Hee Yeul Woo

University of California, Davis

April 12, 2012

Paper \# 12-4

In modern elections, ideologically motivated candidates with a wealth of information about individual voters and sophisticated campaign strategies are faced by voters who lack awareness of some political issues and are uncertain about the exact political positions of candidates. This is the context in which we analyze electoral competition between two ideologically fixed candidates and a finite set of voters. Each political issue corresponds to a dimension of a multidimensional policy space in which candidates' and voters' most preferred policy points are located. Candidates can target messages to subsets of voters. A candidate's message consists of a subset of issues and some information on her political position in the subspace spanned by this subset of issues. The information provided can be vague, it can be even silent on some issues, but candidates are not allowed to bluntly lie about their ideology. Every voter votes for the candidate she expects to be closest to her but takes into account only the subspace spanned by the issues that come up during the campaign. We show that any prudent rationalizable election outcome is the same as if voters have full awareness of issues and complete information of policy points, both in parliamentary and presidential elections. We show by examples that these results depend on the strength of electoral competition, the ability to target information to voters, and the political reasoning abilities of voters.

Department of Economics

One Shields Avenue

Davis, CA 95616

(530)752-0741

http://www.econ.ucdavis.edu/working_search.cfm 


\title{
Political Awareness and Microtargeting of Voters in Electoral Competition*
}

\author{
Burkhard C. Schipper ${ }^{\dagger} \quad$ Hee Yeul $\mathrm{Woo}^{\ddagger}$
}

April 12, 2012

\begin{abstract}
In modern elections, ideologically motivated candidates with a wealth of information about individual voters and sophisticated campaign strategies are faced by voters who lack awareness of some political issues and are uncertain about the exact political positions of candidates. This is the context in which we analyze electoral competition between two ideologically fixed candidates and a finite set of voters. Each political issue corresponds to a dimension of a multidimensional policy space in which candidates' and voters' most preferred policy points are located. Candidates can target messages to subsets of voters. A candidate's message consists of a subset of issues and some information on her political position in the subspace spanned by this subset of issues. The information provided can be vague, it can be even silent on some issues, but candidates are not allowed to bluntly lie about their ideology. Every voter votes for the candidate she expects to be closest to her but takes into account only the subspace spanned by the issues that come up during the campaign. We show that any prudent rationalizable election outcome is the same as if voters have full awareness of issues and complete information of policy points, both in parliamentary and presidential elections. We show by examples that these results depend on the strength of electoral competition, the ability to target information to voters, and the political reasoning abilities of voters.
\end{abstract}

Keywords: Electoral competition, multidimensional policy space, microtargeting, dog-whistle politics, ideological candidates, verifiable information, unawareness, framing, prudent rationalizability, forward-induction.

JEL-Classifications: C72, D71, P16.

*We thank Pierpaolo Battigalli, Oliver Board, Giacomo Bonanno, Jon Eguia, Ignacio Esponda, Boyan Jovanovic, Jean-François Laslier, Alessandro Lizzeri, Tymofiy Mylovanov, Joaquim Silvestre, and seminar participants at NYU Stern for helpful comments. Burkhard is grateful for financial support from the NSF SES-0647811.

${ }^{\dagger}$ Department of Economics, University of California, Davis. Email: bcschipper@ucdavis.edu

${ }^{\ddagger}$ Department of Economics, University of California, Davis. Email: hywoo@ucdavis.edu 


\section{Introduction}

We study to what extent electoral competition can effectively promote awareness of political issues and reveal information about political positions of candidates. To stack the deck against a positive result, our model features a stark asymmetry between voters and candidates. Voters may not think about all political issues and face incomplete information about political positions of candidates, while candidates are aware of all political issues, know perfectly the preferences of voters, and can use modern sophisticated campaign strategies including microtargeting to persuade voters. Nevertheless, we will show that election outcomes under voters' unawareness of many political issues and incomplete information about candidates' political positions are equivalent to election outcomes under full awareness of political issues and complete information about candidate's political positions. We also show that this positive result depends crucially on the strength of electoral competition, the ability of candidates to microtarget voters, and voters' political reasoning abilities.

Traditionally, candidates in electoral competition have been viewed as motivated to win the election by being completely opportunistic in their choice of political positions (i.e., Downs, 1957). While winning the election is an important motivation, we believe that candidates are constrained by their ideology. Politicians insist that their agendas reflect personal convictions (Hillygus and Shields, 2008, p. 40). For instance, during the 2000 presidential campaign, George W. Bush insisted that "we take stands without having to run polls and focus groups to tell us where we stand." (Carney and Dickerson, 2000). Hillygus and Shields (2008) point out, political systems are structured in a way that individuals running for office are more to care about policy outcomes than the average citizen. We believe that parties and lobbies have mechanisms like primary elections that ensure the selection of ideologically motivated candidates (for empirical support, see for instance Brady, Han, and Pope, 2007). Thus, we will assume in our model that each candidate has a fixed political position.

The political positions of candidates may not be obvious to all voters and may pertain to many political issues that are shaping the complex political environment of an election. For instance, the University of Wisconsin Advertising Project identified more than 70 issues in the 2004 presidential campaign including government spending, minimum wages, immigration, abortion, homosexuality, gun control, narcotics, education, terrorism etc. We will assume that candidates have a fixed political position in a multidimensional 
policy space in which each dimension corresponds to an issue.

Candidates may raise only some political issues in a campaign but may be completely silent on others. On some of political issues raised, candidates may be intentionally vague about their political position while on others they may be completely transparent. Moreover, they may intentionally communicate some information on some of those issues to some voters only but not to all voters. For instance, in the 2000 presidential campaign, Bush sent a letter to the U.S. Conference of Catholic Bishops, who weight influence over a traditional Democratic constituency, in which he pledged that taxes should not be used to fund research that involves the destruction of human embryos. Yet, stem cell research was not mentioned in nominated speeches of either candidate, not covered on their television advertising, not raised in presidential debates nor displayed on campaign web sites (see Hillygus and Shields, 2008, p. 2). This is an example of political campaigning that targets a subset of voters. Hillygus and Shields (2008, p. 5-6) write "(T)the contemporary information environment has made it easier ... to target issue messages to narrow segments of the population. With a wealth of information about individual voters, candidates are increasingly able to microtarget personalized appeals on the specific issues for which each voter disagrees with the other candidate. This fragmentation of the candidates' campaign communications leads to dog-whistle politics - targeting a message so that it can be heard only by those it is intended to reach, like the highpitched dog whistle that can be heard by dogs but is not audible to the human ear. By narrowly communicating issue messages, candidates reduce the risk of alienating other voters, thereby broadening the range of issues on the campaign agenda. For instance, our analysis finds that the candidates in the 2004 presidential election staked positions on more than seventy-five different policy issues in their direct-mail communications. Thus, new information and communication technologies have changed not only how candidates communicate with voters, but also who they communicate with and what they are willing to say." In our model, we will allow for sophisticated targeting of voters with specific campaign messages and issues. ${ }^{1}$

\footnotetext{
${ }^{1}$ This seems to be contrast to most of the theoretical literature on electoral competition. For instance, Laslier (2006), who presents an interesting study of ambiguity in electoral competition, writes that "(p)olitical communication is mass communication. If a politician was able to design a different talk for each elector, maybe each of these talks would be very clear. Actually, politicians can easily give way to the temptation of making different promises to different people." He further writes "(a)n ambiguous electoral platform may be understood differently by individuals, and politicians would like to target their messages at different electors. For practical reasons, it is impossible to perfectly realize this targeting. From the
} 
In order to successfully tailor campaign messages to voters, candidates need to know political preferences of voters. In the past, it was impossible for candidates to know individual political preferences of voters. Rather, they had to be content with aggregate information about voters' preferences from opinion polls or similar. Yet, modern information technology allows to collect a wealth of individual data on voters, apply sophisticated data mining tools, and use this information strategically in campaigns. Recent campaigns merged voter registration files with consumer data that include names, addresses, address histories, driving records, criminal records, and consumer purchases like magazine subscriptions, mortgage information, credit-card purchases, gun ownership etc. (see Hillygus and Shields, 2008, p. 159, 161). ${ }^{2}$ This information was then used to "microtarget messages through direct mail, email, telephone calls, and personal visits." As Sara Taylor, a strategist for Bush's 2004 presidential campaign summed up "We could identify exactly who should be mailed, on what issues, and who should be ignored completely." (Hillgus and Shields, 2008, p. 161). We reflect this "transparent" voter in our model by assuming that candidates have perfect information about voters' most preferred policy points.

So far, we painted a picture of elections in a complex political environment with many issues and with candidates who hold fixed political positions, know perfectly voters' preferences and use sophisticated campaign strategies including microtargeting messages to subsets of voters. On the voters side we assume that voters may have limited political

normative point of view, it is interesting to consider that a party cannot at all target its communication at different voters. This simply corresponds to an hypothesis of equal information of the electors as to the partys platform." In light of the empirical evidence about modern election campaign strategies such as microtargeting, we take the view that not all political communication is mass communication in the public sphere but that candidates can communicate also privately with voters. We study what may happen if the traditional assumption of political communication being exclusively public is given up.

${ }^{2}$ There are several commercial companies in the US like Aristotle, Camelot, and Catalist who collect individual voter records, merge them with other public and commercial data, and provide them for a fee to campaigns. For instance, Catalist claims to maintain a "database of over 265 million persons (more than 180 million registered voters and 85 million unregistered adults)". The data include "Registered Voters and Non-Registered persons (with contact information)" but also "Commercial and Census Data ..." (see http://catalist.us). The company Aristotle claims that "(i)n addition to the wealth of demographics Aristotle already provides for high level micro-targeting, you can now identify your voters based on their interests and hobbies. Aristotle maintains a list of over 5.4 million voters who hold hunting and fishing licenses, as well as individuals who subscribe to a wide array of magazine subscriptions including family, religious, financial, health, culinary and Do-It Yourself publications." Premium data are priced at $\$ 0.06$ per record for over 50,000 records (see http://www.aristotle.com or http://www.voterlistsonline.com). 
awareness in that they do not take all political issues into account when forming their preferences over candidates. Moreover, they face incomplete information about candidates' political positions on issues they are aware of. In electoral competition, candidates may raise some political issues to some subset of voters and other issues to other voters, and provide more or less precise information about their political positions on those issues to selected subsets of voters. Despite the extreme asymmetric awareness and information between candidates and voters, we will show that in elections with two candidates, election outcomes are the same as under full awareness and complete information. This holds for both presidential elections in which candidates care about only winning the election, as well as parliamentary elections in which candidates care about only their share of voters.

To provide some intuition, we like to sketch here some features of a simplified model. Consider two candidates and just one voter. Focusing on one voter allows us to explain more transparently some features of our model. The policy space is a multidimensional Euclidean space. Each issue corresponds to a dimension and the political positions of the candidates and the most preferred policy point of the voter are points in this space. The voter evaluates a candidate by how far the candidate's policy point is away from his most preferred policy point using Euclidean distance but only in a subspace spanned by the issues that he is aware of. Assume first that the voter is unaware of all but one issue and that candidates can campaign by raising issues to him. Further, we assume for the moment that once an issue has been raised by some candidate, the political positions of both candidates on this issue becomes completely transparent to the voter. Finally, we assume that both candidates know the voter's most preferred policy point and each other's political positions. We claim that in this extremely simplified model candidates will raise enough issues so as to produce a vote that would emerge also under full awareness of all issues. To see this note that candidates face a zero-sum game. If raising an issue is not beneficial to one candidate, it will be to the other. Thus, either all issues will be raised or raising further issues won't change the vote anymore. Now assume that policy points on issues that have been raised do not become automatically transparent. Each candidate can provide some information on her political position. We assume that this information can be vague, that a candidate can be silent on issues, but that she can not bluntly lie in the sense of not including her political position (in the subspace of issues revealed) in the information she provides. This is reminiscent of models of verifiable information à la Grossman (1981), Milgrom (1981), and Milgrom 
and Roberts $(1986)^{3}$ except that our model involves unawareness of some dimensions of the information and more than one informed party. ${ }^{4}$ We claim that despite unawareness and incomplete information, all "relevant" information is revealed to the voter. To see this, note that a voter should realize that if a candidate does not provide more precise information on an issue that he is aware of, then it is because this information is not favorable to the candidate. This is a version of forward-induction reasoning embodied in the solution concept that we employ.

Different from a model without unawareness, this unraveling result depends crucially on the strength of electoral competition. For instance, in former socialist countries like the German Democratic Republic, "elections" consisted mainly of voting 'Yes' or 'Abstain' on a single list of candidates. There was no choice between the candidates possible. ${ }^{5}$ We show in Section 5.1 that if there is only the choice between a candidate and a passive "status quo" (i.e., a passive candidate in the sense of not campaigning at all), then our result may break down. This is different from standard models of verifiable information without unawareness à la Grossman (1981) and Milgrom (1981) in which even with a single "sender" there is full unraveling of information.

With more than one voter, we potentially face well-known limits to aggregation of voters' preferences. In particular, since voters can have probabilistic beliefs about candidates' political positions, a candidate may find it useful to keep a voter uncertain about his political position. ${ }^{6}$ In particular, the "preference" of society may not correspond to a von Neumann-Morgenstern utility function even though each voter's preference is cap-

\footnotetext{
${ }^{3}$ See also Okuno-Fujiwara, Postlewaite, and Suzumura (1990) and Battigalli (2006). The latter author employs a solution concept similar to ours.

${ }^{4}$ The nihilistic popular opinion about politicians may dispute the assumption that politicians do not lie. But we believe that even politicians refrain from lying bluntly but rather resort to being vague about their positions or keeping quiet on some issues (and thus appear to provide "misleading information"), both features that we seek to analyze here. We also like to point out that standard models of electoral competition à la Downs (1957) do assume that politicians do not lie. See Callander and Wilkie (2007) for a rare study of lies in electoral competition.

${ }^{5}$ Except for the last election in 1989, upon arrival at the ballot station voters were handed a list with the "Kandidaten der Nationalen Front" that they were supposed to put into the ballot box under the supervision of "helpers". In the last election in 1989 before the "Wende", polling boothes were provided for the first time. Voters had the choice of using the polling booth to cross out the entire list of candidates, but there was still no alternative list of candidates.

${ }^{6}$ Related problems have been noted in Zeckhauser (1969) and Shepsle (1970, 1972).
} 
tured by a von Neumann-Morgenstern utility. In Section 4 we present a simple example with three voters, in which one and the same candidate is elected if each of the possible political positions of the candidates were commonly known but the other candidate is elected under uncertainty over the candidate's political positions. In this sense, there is a role for "ambiguity" in electoral competition. ${ }^{7}$ We note that this problem arises only if candidates are forced to provide the same (public) information to all voters. In this case, a voter not receiving more precise information cannot deduce that the candidate's political position is not favorable to him because it may just be unfavorable to some other voters and that's the reason why this more precise information is not communicated by the candidate. Last issue can be circumvented in our model by allowing targeted campaigning as motivated above, in which candidates can provide differently precise information to different voters. This highlights a somewhat unexpected role for targeted campaigning that has previously been viewed as having problematic impacts on democracy. For instance, Hillygus and Shields (2008, pp. 13) write "The fragmentation of campaign dialogue also has potential implications beyond the electoral contest itself. Elections have always been a blunt instrument for expressing the policy preferences of the public but the multiplicity of campaign messages makes it even more difficult to evaluate whether elected representatives are following the will of the people. Microtargeting enables candidates to focus attention on the issues that will help them win, irrespective of whether they are of concern to the broader electorate. In the months leading up to the 2004 Democratic National Convention, for instance, the monthly Gallup Poll open-ended question asking about the most important problem facing the nation never once registered stem cell research in its top twenty issues. It is also hard to imagine that snowmobiling policy topped the public's list of political concerns in 2006, but in the Michigan governor's race, Republicans microtargeted working-class snowmobilers with the message that the Democratic candidate's environmental views stood in the way of better snowmobiling opportunities. Will political dialogue be consumed by 'superficial politics' instead of addressing critical issues of concern to the general public? How does a winning candidate interpret the policy directive of the electorate if different individuals intended their vote to send different policy messages? Can politicians claim a policy mandate if citizens are voting on the basis of different policy promises?" Our observations in this paper may caution about an entirely negative assessment of microtargeting

\footnotetext{
${ }^{7}$ This topic lead to an extensive literature with different approaches. See Downs (1957), Shepsle (1972), Alesina and Cukierman (1990), Aragonès and Neeman (2000), Aragonès and Postlewaite (2007), Glazer (1990), Jensen (2009), Laslier (2006), McKelvey (1980), Meirowitz (2005), and Page (1976).
} 
voters because we are able to demonstrate in our model that microtargeting voters with different messages enables effective information revelation as a voter can now deduce from the fact that a candidate has not provided precise information on her political position that her true position is unfavorable to the voter. It also suggests that "ambiguity" in electoral competition may be due in part to imperfect microtargeting of voters.

It may be argued that casual empirical evidence suggests that electoral competition does not reveal sufficiently "relevant" information. In this case, our theory offers a useful map for discovering culprits for the lack of information unraveling. Some of our modeling assumptions must be violated. This is how we view the main contribution of the positive result. In Section 5, we discuss with examples how the result breaks down under various conditions. We previously mentioned that lack of electoral competition and the inability to microtarget messages may limit the unraveling of information in electoral campaigns. There may be another empirically relevant reason: Although we assume that voters may be unaware of some political issues and face incomplete information about candidates' political positions, we still attribute to them quite sophisticated political reasoning that is embodied in our solution concept. We show in Section 5.3 how our positive result may break down if they lack sophisticated political reasoning.

Allowing for dynamically changing multidimensional policy spaces and voters who are aware of different subspaces only and who may become aware of larger subspaces during the political campaign poses a modeling challenge in terms of tractability. ${ }^{8}$ To model such limited awareness in a dynamic strategic context, we will make use of generalized extensive-form games with unawareness introduced in Heifetz, Meier, and Schipper (2011a). ${ }^{9}$ Such a game consists of a collection of game trees partially ordered by a subtree relation. Initially a player may be unaware of some dimension of the problem and perceive the strategic situation as a subtree. During the course of play, he may become aware of more and more dimensions and perceive increasingly richer subtrees as the description of

\footnotetext{
${ }^{8}$ Our model can be viewed as an answer to an early critique in political science of the uni-dimensional Downs model. Stokes (1963) postulated that "the space in which political parties compete can be of highly variable structure. Just as the parties may be perceived and evaluated on several dimensions, so the dimensions that are salient to the electorate may change widely over time." He also criticized the assumption of a commonly perceived policy space by stating "(b)ut with the space formed out of perceptions, there is no logically necessary reason why the space of voters and of parties should be identical, and there is good empirical reason to suppose that it often is not."

${ }^{9}$ See Halpern and Rego (2006), Li (2006), Feinberg (2009), Grant and Quiggin (2011), and Ozbay (2007) for related work.
} 
the strategic situation. Because players cannot anticipate on which dimensions exactly they will become aware of in future, there may not be a natural equilibrium convention that could have been learned in the past. Therefore we will make use of prudent rationalizability, a version of extensive-form rationalizability à la Pearce (1984) and Battigalli (1997) that has been introduced for generalized extensive-form games in Heifetz, Meier, and Schipper (2011b). It is a strong solution concept that entails forward-induction. In perfect information game it yields outcomes that are equivalent to outcomes reached with iterated admissibility (see Meier, and Schipper, 2012), a solution concept that has a long tradition in political economy models and in voting games (see Farquharson, 1969, Brams, 1975, Moulin, 1979, and Gretlein, 1982). It is an iterative solution concept that also allows us to study behavioral implications for every finite level of rationalization and thus implications of limited political reasoning (see Section 5.3).

The paper is organized as follows: The next section we introduce the model. This is followed by two simple examples in Section 3. In Section 4 we state and prove the main results. Limitations and counterexamples are discussed in Section 5. We conclude in Section 6, where we also discuss further related literature. The proofs are collected in an appendix.

\section{Model}

Let $I=\{1, \ldots, m\}$ be a finite set of political issues. Examples of issues are "Iraq War", "Abortion", "Health Care" etc. ${ }^{10}$ Different policies with regard to an issue are associated with different points in the real interval $[0,1]$, one interval for each issue. Thus, the fulldimensional policy space considered in this model is $[0,1]^{|I|}$. Since we aim to study electoral competition when some voters may not be aware of all issues, we also need to consider subspaces of the full-dimensional policy space. For any nonempty subset of issues $I^{\prime}$ and $I^{\prime \prime}$ with $\emptyset \neq I^{\prime} \subseteq I^{\prime \prime} \subseteq I$, denote the projection by $r_{I^{\prime}}^{I^{\prime \prime}}:[0,1]^{\left|I^{\prime \prime}\right|} \longrightarrow[0,1]^{\left|I^{\prime}\right|}$. We let $Y$ denote a finite set of policy points in $[0,1]^{|I|}$. For every nonempty subset $I^{\prime}$ of issues, $I^{\prime} \subseteq I$, let $Y_{I^{\prime}}$ be the projections of policy points in $Y$ onto the subspace $[0,1]^{\left|I^{\prime}\right|}$ spanned by $I^{\prime}$.

There are two candidates, $a$ and $b$. Each candidate $k \in\{a, b\}$ has a fixed ideological

\footnotetext{
${ }^{10} \mathrm{We}$ acknowledge that these issues themselves may be multidimensional. In this case, we would consider each dimension as an issue.
} 
policy point $y^{k} \in Y$. If candidate $k$ 's political position in $Y$ is $y^{k}$, then for any nonempty $I^{\prime} \subseteq I$ his political position in $Y_{I^{\prime}}$ is $r_{I^{\prime}}^{I}\left(y^{k}\right)$. We sometimes write $y_{I^{\prime}}^{k}$ for $r_{I^{\prime}}^{I}\left(y^{k}\right)$.

There is a finite set of voters denoted by $N=\{1, \ldots, n\}$. Each voter $j \in N$ has a unique most preferred policy point $x^{j}$ in the full-dimensional policy space, $[0,1]^{|I|}$, with projections denoted by $x_{I_{I^{\prime}}}^{j}$ for any nonempty $I^{\prime} \subseteq I$.

A voter $j$ 's utility from candidate $k$ depends on voter $j$ 's awareness of political issues and is given by the Euclidean distance between his most preferred point and the candidate's policy but only in the subspace of issues that he is aware of. I.e., the utility of voter $j$ from voting for candidate $k$ when voter $j$ is aware of issues in $I^{\prime}$ with $\{1\} \subseteq I^{\prime} \subseteq I$ and candidate $k$ 's political position on these issues is $y^{k} \in Y_{I_{I^{\prime}}}$ is ${ }^{11}$

$$
u^{j}\left(I^{\prime}, y^{k}, x^{j}\right)=-\left\|x^{j}-y^{k}\right\|_{I^{\prime}}:=-\sqrt{\sum_{i \in I^{\prime}}\left(x_{i}^{j}-y_{i}^{k}\right)^{2}} .
$$

We assume that at the beginning of the campaign voters are aware of only one default issue, which is issue 1 . That is, even when neither candidate raises any issue, voters are aware of issue 1 and the set of all possible policy points of candidates, $Y_{\left.\right|_{\{1\}}}$, regarding issue 1. It allows for well-defined preferences of voters even if no issues are raised in the campaign. $^{12}$

We start with describing one game tree denoted by $T^{I}$. At the first stage of $T^{I}$, nature $c$ (i.e., "chance") moves and selects for each candidate a most preferred policy point in the finite set $Y \subseteq[0,1]^{|I|}{ }^{13}$ We assume that candidates have complete information about

\footnotetext{
${ }^{11}$ Note that the Euclidean distance will typically increase with an increasing number of dimensions.
} That is, revealing further dimensions to voters may decrease their utility. We could use a "dimensionnormalized" Euclidean distance, $\sqrt{\frac{1}{\left|I^{\prime}\right|} \sum_{i \in I^{\prime}}\left(x_{i}^{j}-y_{i}^{k}\right)^{2}}$ instead (and our results would follow too). Yet, despite the fact that raising additional dimensions decreases the utility of voters, we will show an unraveling result. The use of the Euclidean distance may be defended with the argument that most political issues are perceived as "problems" and thinking about them may causes disutility per se. Such a "hedonic" argument is misguided when utilities are viewed purely as decision weights. Nothing in our model depends on the interpretation of utilities. This is because voters make decisions to cast the vote for candidate $a$ or $b$ always given one awareness level (i.e., subset of political issues) although they can contemplate how they would make decisions given any counterfactual lower awareness level. We conjecture that our results remain true if we consider more generally single peaked preferences of voters.

${ }^{12}$ Our results do not depend on the fact that ex ante all voters are aware of the same default issue. We could allow that ex ante different voters are aware of different subset of issues and our results would remain true.

${ }^{13}$ We don't require a (common) prior probability distribution over moves of nature. Our results do 
each other's political positions (and the voters' most preferred policy points). That is, each of their information sets is a singleton. After the move of nature, candidates simultaneously campaign for votes. In this campaign, each candidate reveals to each voter some subset of issues and some information (i.e., a nonempty subset of policy points) about her own political position on these issues. The information provided to a voter is observed by this voter only and not by other voters (i.e., microtargeting).

After the campaign, each voter votes for a candidate and the game ends. For the vote, each voter takes into account her awareness of issues and the (inferred) information on the candidates' political positions. Since not all issues may have been raised during the campaign, a voter may not be aware of all issues. Consequently, she is unable to think about these issues and does not realize that they could have been raised in a different campaign. This means that the voter's information set emanating from a node in the tree $T^{I}$ may be a subset of corresponding nodes in a poorer description of the game in which nature chooses policy points of candidates only in space spanned by a subset of issues and where candidates can raise only subsets of this subset of issues during the campaign and provide information on those raised issues to voters. That is, our model involves a collection of trees, $\left(T^{I^{\prime}}\right)_{\{1\} \subseteq I^{\prime} \subseteq I}$, one for each subset of issues that includes the default issue. For each $T^{I^{\prime}},\{1\} \subseteq I^{\prime} \subseteq I$, nature selects a profile of candidates' (projected) policy points in $Y_{I^{\prime}} \times Y_{I^{\prime}} \subseteq[0,1]^{\left|I^{\prime}\right|} \times[0,1]^{\left|I^{\prime}\right|}$. In the tree $T^{I^{\prime}}$, candidates have complete information about those policy points, i.e., singleton information sets. Candidates campaign simultaneously for votes by revealing to each voter some (possibly proper) subset of issues in $I^{\prime}$ and some information on their own political positions on these issues. After the campaign, voters vote on candidates taking only the subset of issues raised during this campaign and information provided in this campaign into account when forming their expectations. That is, a voter's information set emanating from a node in the tree $T^{I^{\prime}}$ may be a subset of corresponding nodes in an even poorer description of the game $T^{I^{\prime \prime}}$ with $1 \subseteq I^{\prime \prime} \subset I^{\prime}$. Note that an information set of a voter may contain several nodes (within one tree) because of the uncertainty over the policy points of candidates on the issues they are aware of.

To complete the description of the game, we need to specify preferences. We assume that voters vote sincerely. That is, each voter votes for the candidate that is "closest" to her given her awareness and information. She assigns the utility given in equation (1) to any terminal history in which she voted for candidate $k$, nature selected $y^{k}$, and $I^{\prime}$ is the

not depend on prior beliefs about candidates' most preferred policy points. 
union of sets of issues that were raised during the campaign by either candidate $a$ or $b$.

For candidates we consider two types of preferences. For any terminal node $z$, let $\sigma(z)(a)$ be the share of voters voting for candidate $a$. Candidates care only about winning the election if the utility function of candidate $a$ is defined by

$$
u^{a}(z)=\left\{\begin{aligned}
1 & \text { if } \sigma(z)(a) \geq \frac{1}{2} \\
-1 & \text { otherwise }
\end{aligned}\right.
$$

and candidate $b$ 's utility function is given by

$$
u^{b}(z)=-u^{a}(z)
$$

For simplicity we don't allow for ties in payoffs but confer to candidate $a$ a slight advantage in case both candidates obtain the same number of votes. ${ }^{14}$ For reasons motivated in the introduction, we call the game in which candidates care only about winning the election the presidential election model. It has been also called the "majority tournament" in the literature (see for instance, Laslier, 2005).

Candidates care only about the share of voters if the utility function of candidate $a$ is defined by

$$
u^{a}(z)=\sigma(z)(a)
$$

and candidate $b$ 's utility function is given by

$$
u^{b}(z)=1-u^{a}(z)
$$

Note that both specifications of utility functions make the game into a strictly competitive game for candidates. Again, for reasons discussed in the introduction, we call the game in which candidates care about the share of voters the parliamentary election model. It has been also called the "plurality game" in the literature (see for instance, Laslier, 2005).

The collection of game trees partially ordered by set inclusion on the set of issues and the information sets outlined above shall satisfy the properties of generalized extensiveform games introduced in Heifetz, Meier, and Schipper (2011a).

\footnotetext{
${ }^{14}$ Alternatively, we could have required as often done in the literature the number of voters to be odd. While latter assumption would simplify the proofs slightly, we opted for the first assumption for two reasons. First, in reality there is often an incumbent who may have a slight advantage over the other candidate. Second, we are just interested in comparing election results under incomplete information and unawareness with election results under full information and awareness. The tie breaking assumption is not important as long as it is the same under both scenarios.
} 
For any nonempty subset $I^{\prime},\{1\} \subseteq I^{\prime} \subseteq I$, the $I^{\prime}$-partial game is the collection of the tree $\left(T^{I^{\prime \prime}}\right)_{\{1\} \subseteq I^{\prime \prime} \subseteq I^{\prime}}$ such that all information sets emanating at nodes in the trees of this collection are contained within trees of this collection.

For $k \in N \cup\{a, b\}$ we denote by $H_{k}$ the set of all information sets of player $k$ (across all trees) and by $I\left(h_{k}\right)$ be the set of issues such that information set $h_{k}$ belongs to the tree $T^{I\left(h_{k}\right)}$.

\section{$2.1 \quad$ Strategies}

Let $I^{k, j} \subseteq I$ be the set of issues raised by candidate $k \in\{a, b\}$ to voter $j \in N$. To ease notation we assume that each candidate raises at least the default issue 1 to each voter, i.e., $\{1\} \subseteq I^{k, j}, k \in\{a, b\}, j \in N$.

When deciding to vote for one candidate or another, each voter $j$ takes into account only issues that are raised to him during the campaign by either candidate (apart from the default issue). For instance, if candidate $a$ campaigned to voter $j$ on issues in the set $I^{a, j}$ and candidate $b$ campaigned to voter $j$ on issues in $I^{b, j}$, then voter $j$ takes into account issues in $I^{a, j} \cup I^{b, j} \subseteq I$. That is, the policy space perceived by voter $j$ is restricted to the domain $[0,1]^{\left|I^{a, j} \cup I^{b, j}\right|}$.

A strategy of voter $j$ is a function that assigns to each information set of voter $j$ a candidate she votes for. That is,

$$
s_{j}: H_{j} \longrightarrow\{a, b\} .
$$

Note that a voter's strategy assigns to each of the voter's information sets in each tree the candidate for which he votes. Since a voter may be unaware of many policy issues and consequently may not perceive all trees, he can not "choose" such a strategy ex ante before the game commences. Rather, at each of his information sets the voter chooses an action. Strategies of voters will be used here just as objects of candidate's beliefs. As we will see below, candidates form beliefs about the behavior of voters.

For each candidate $k \in\{a, b\}$, let $y^{k}\left(h_{k}\right)$ be the policy point selected by nature in $Y_{I_{I\left(h_{k}\right)}}$ after which information set $h_{k}$ of candidate $k$ occurs. That is, $y^{k}\left(h_{k}\right)$ is candidate $k$ 's policy point selected by nature on the path to $h_{k}$. A strategy for candidate $k \in$ $\{a, b\}$, specifies for each information set $h_{k} \in H_{k}$ of candidate $k$ which issues and which information on those issues she provides to each voter. We assume that each candidate can not bluntly lie about her policy point but she can be vague. That is, if $I^{k, j} \subseteq I\left(h_{k}\right)$ 
is the nonempty set of issues provided by candidate $k$ to voter $j$ at information set $h_{k}$, then her (projected) policy point $y^{k}\left(h_{k}\right)_{I^{k, j}}$ must be in the set of policy points provided by candidate $k$ to voter $j$ at the information set $h_{k} \cdot{ }^{15}$ This assumption generalizes the model of verifiable information à la Grossman (1981) and Milgrom (1981) to a multidimensional setting with possible unawareness of some dimensions by the receiver. Note that candidate $k$ in her message to voter $j$ at the information set $h_{k}$ can be silent on some issues in $I\left(h_{k}\right)$. Finally, we do not require that the same set of issues and information is provided to each voter, i.e., we allow for microtargeting of voters. Formally, a strategy for candidate $k \in\{a, b\}$ is

$$
s_{k}: H_{k} \longrightarrow \prod_{j \in N}\left[\bigcup_{\{1\} \subseteq I^{j} \subseteq I} 2^{Y_{I^{j}}}\right]
$$

such that for every voter $j \in N$, there exists $I^{j}$ with $\{1\} \subseteq I^{j} \subseteq I\left(h_{k}\right)$ such that $y^{k}\left(h_{k}\right)_{I_{I^{j}}} \in\left(s_{k}\left(h_{k}\right)\right)_{j} \in 2^{\left.Y\right|_{I^{j}}}$, where $\left(s_{k}\left(h_{k}\right)\right)_{j}$ is the $j$ th component in the profile $s_{k}\left(h_{k}\right)$. With this notation, $\left(s_{k}\left(h_{k}\right)\right)_{j}$ is the information provided by candidate $k$ to voter $j$, i.e., it is a subset of policy points in some policy space that includes candidate $k$ 's "true" policy point in this space. Note that candidate $k$ 's "true" policy point $y^{k}\left(h_{k}\right)_{\left.\right|_{I^{j}}}$ at the information set $h_{k}$ (subject to possibly being silent on some issues) is required to be in the set of possible policy points $\left(s_{k}\left(h_{k}\right)\right)_{j}$ provided to voter $j$.

For $k \in N \cup\{a, b\}$ we denote by $S_{k}$ player $k$ 's set of strategies. Moreover, for any strategy $s_{k} \in S_{k}$ and any subset $I^{\prime}$ of issues with $\{1\} \subseteq I^{\prime} \subseteq I$, we denote by $s_{k}^{I^{\prime}}$ the $I^{\prime}$-partial strategy in the $I^{\prime}$-partial game induced by $s_{k}$. This is the strategy $s_{k}$ restricted to $k$ 's information sets in the $I^{\prime}$-partial game. $S_{k}^{I^{\prime}}$ denotes the set of $I^{\prime}$-partial strategies of player $k$.

\subsection{Belief Systems}

Each voter forms beliefs about candidates' policy points and (partial) strategies. For every information set of the voter, his belief is restricted to issues that the voter is aware of. Voter $j$ 's belief system is a tuple

$$
\left(\beta_{j}\left(h_{j}\right)\right)_{h_{j} \in H_{j}} \in \prod_{h_{j} \in H_{j}} \Delta\left(Y_{\left.\right|_{I\left(h_{j}\right)}} \times Y_{\left.\right|_{I\left(h_{j}\right)}} \times S_{a}^{I\left(h_{j}\right)} \times S_{b}^{I\left(h_{j}\right)}\right)
$$

\footnotetext{
${ }^{15}$ We could have imposed this restriction on the generalized extensive-form game itself rather than on strategies of candidates. However, in order to avoid additional notation we opted to impose it as a restriction on candidates' strategies.
} 
such that for all $h_{j}, \beta_{j}\left(h_{j}\right)$ assigns probability 1 to the subset of candidates' policy points selected by nature in $Y_{I_{\left(h_{j}\right)}} \times Y_{\left.\right|_{I\left(h_{j}\right)}}$ and candidates' strategy profiles in $S_{a}^{I\left(h_{j}\right)} \times S_{b}^{I\left(h_{j}\right)}$ that reach $h_{j}$ in the $I\left(h_{j}\right)$-partial game. That is, at every of his information sets $h_{j}$, voter $j$ is certain to have reached his information set $h_{j}$.

For two information sets $h$ and $h^{\prime}$ in a given tree $T^{I^{\prime}}$, we say $h$ precedes $h^{\prime}$ (or $h^{\prime}$ succeeds $h$ ) if for node $n^{\prime} \in h^{\prime}$, there is a path $n, \ldots, n^{\prime}$ in $T^{I^{\prime}}$ such that $n \in h{ }^{16}$

At every information set of candidate $k \in\{a, b\}$, we assume that she knows her policy point and the policy point of the opponent candidate $-k$ selected by nature. She forms beliefs about the other candidate's strategy and the strategies of voters. For $k \in\{a, b\}$, candidate $k$ 's belief system is a tuple

$$
\left(\beta_{k}\left(h_{k}\right)\right)_{h_{k} \in H_{k}} \in \prod_{h_{k} \in H_{k}} \Delta\left(S_{-k}^{I\left(h_{k}\right)} \times \prod_{j \in N} S_{j}^{I\left(h_{k}\right)}\right) .
$$

For $k \in N \cup\{a, b\}$, we denote by $B_{k}$ the collection of player $k$ 's belief systems.

\subsection{Prudent Rationalizability}

In our model, voters may not think about all political issues before the election and consequently may be surprised about the issues arising in the campaign. Thus, it would be inappropriate to assume that voters could have always learned an equilibrium convention that is guiding their behavior. Instead, we will make use of a solution concept that embodies "political reasoning" in the sense that voters asked themselves why candidates provided them with this or that information and why they raised this or that political issue. Our iterative solution concept called prudent rationalizability has been introduced in Heifetz, Meier, and Schipper (2011b) for generalized extensive-form games with unawareness. It is a version of extensive-form rationalizability (see Pearce, 1984, and Battigalli, 1997) featuring cautious behavior and an extensive-form analogue to iterated admissibility.

For any player $k \in N \cup\{a, b\}$, with a belief system $\beta_{k}$, a strategy $s_{k}$ of player $k$ is rational at information set $h_{k} \in H_{k}$, if there exists no other action $s_{k}^{\prime}\left(h_{k}\right)$ at $h_{k}$ such

\footnotetext{
${ }^{16}$ We could require a belief system to satisfy Bayesian updating whenever possible. Yet, Bayesian updating whenever possible will be implied by our solution concept. See Meier and Schipper (2012) and (for standard games and standard extensive-form rationalizability) Shimoji and Watson (1998).
} 
that by only replacing the action $s_{k}\left(h_{k}\right)$ with action $s_{k}^{\prime}\left(h_{k}\right)$ (which results in some new strategy) yields $k$ a strictly higher expected utility.

Prudent rationalizability adapted to our context takes the following form:

Definition 1 (Prudent Rationalizability) For $k \in N \cup\{a, b\}$, let

$$
S_{k}^{0}=S_{k} .
$$

For $\ell \geq 1$, define inductively for $k \in\{a, b\}$,

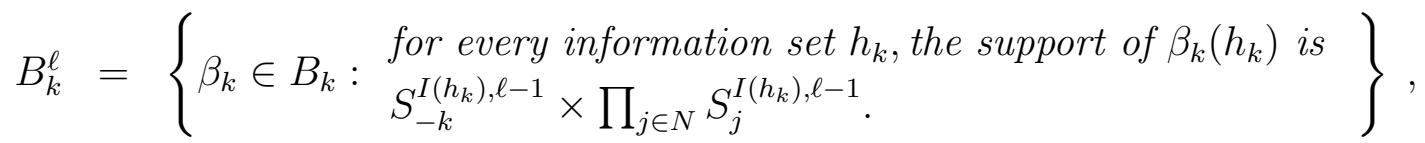

for $j \in N$

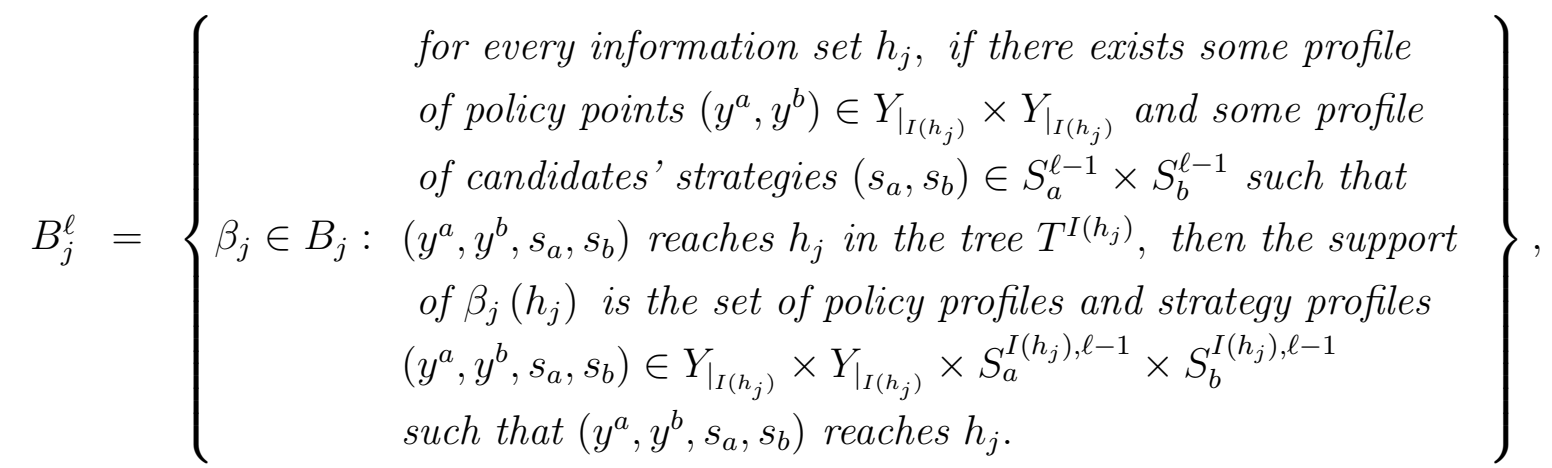

and for any player $k \in N \cup\{a, b\}$,

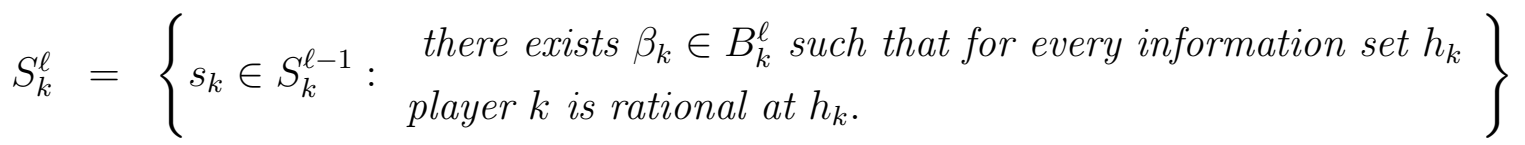

The set of prudent rationalizable strategies of player $k \in N \cup\{a, b\}$ is

$$
S_{k}^{\infty}=\bigcap_{\ell=1}^{\infty} S_{k}^{\ell}
$$

At each level of prudent rationalizability, the prudence or cautiousness of players enters through the full support beliefs about the remaining strategies and possible moves of nature. This feature will be essential for our result. At each round of elimination, a strategy is kept if there exists a full support belief on the remaining strategies of other players and possible moves of nature for which the strategy is rational at every information set of the player. See Heifetz, Meier, and Schipper (2011b) and Meier and Schipper (2012) for discussions of the solution concept.

Since the game is finite, existence of a nonempty set of prudent rationalizable strategy profiles follows directly from a result in Heifetz, Meier, and Schipper (2011b). 


\section{Two Examples}

Before we state and prove our main results, we like to build some intuition and illustrate the definitions with the help of two simple examples.

\subsection{Uni-Dimensional Case}

Consider, as a first simple case, a model with just one issue. There is just a single voter who is aware of this (default) issue. Thus there is no unawareness of issues on part of the voter. The voter's most preferred point is $\frac{5}{12}$ and he is uncertain about the policy points of the two candidates, which are in the set $Y=\left\{\frac{1}{4}, \frac{3}{4}\right\}$.

At the first glance, the case of a single voter may look artificially contrived and uninteresting for the study of electoral competition. After all, elections are about the aggregation of preference of a sizable population of voters. Yet, the model has an interesting reinterpretation since often a political leader such as a president may has to select among two candidates for an important appointment (such as a secretary of state). The two candidates may compete for the appointment by providing more or less precise information about their political preferences on issues that should be considered for this position.

The game form is depicted in Figure 1. Nature moves first and selects the political positions of candidates. Then candidate $a$ moves with information about the political positions. He is followed by candidate $b$ who also knows the political positions but not the information revealed by candidate $a .{ }^{17}$ After the moves of candidates, we reach the information sets of the voter indicated by the blue solid ovals. To save space, the game form is truncated after the information sets of the voter.

A strategy of candidate $k$ is a map $s_{k}: Y \times Y \longrightarrow 2^{Y}$ that assigns to each profile of policy points some information candidate $k$ can reveal about her policy point such that $s_{k}\left(y^{k}, y^{-k}\right) \in\left\{\left\{y^{k}\right\}, Y\right\}$ for any $\left(y^{a}, y^{b}\right) \in Y \times Y$. We let $S_{k}$ denote the set of all strategies of candidate $k$.

\footnotetext{
${ }^{17}$ In the exposition of the model, we stated that candidates move simultaneously while in Figure 1 we let candidate $a$ move before candidate $b$ but let latter not know the move of the first. This is done solely for an easier graphical exposition in Figure 1. Inspired by Dubey and Kaneko (1984), generalized extensive-form games with unawareness of Heifetz, Meier, and Schipper (2011a) used in this paper really do allow for simultaneous moves of players.
} 
Figure 1: Game Form of the Uni-dimensional Example

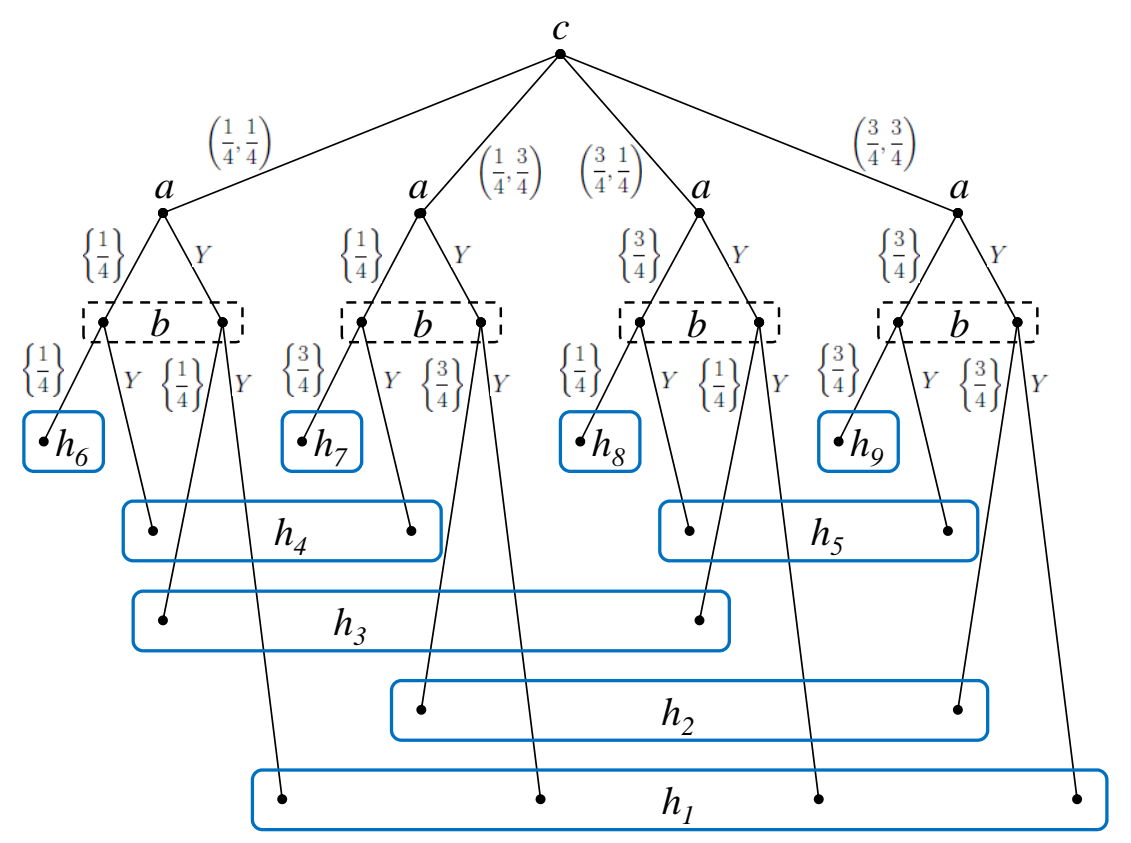

Note that the voter has nine information sets (see Figure 1). Let $H$ denote his set of information sets. A strategy of the voter assigns to each information set the candidate for whom he votes, i.e., $s_{v}: H \longrightarrow\{a, b\}$. Denote by $S_{v}$ the set of all voter's strategies.

We assume that each candidate tries to win the election and the voter likes to vote for the candidate whose policy point is closest to his.

We now apply prudent rationalizability to this example. We will eliminate strategies iteratively. At first level of induction, any candidate $k$ has full support beliefs about all strategies of the other candidate and the voter. For any strategy in $S_{k}$, we can find a full support belief of candidate $k$ such that this strategy is rationalizable. Thus $S_{k}^{1}=S_{k}$.

For the voter, prudent rationalizability has some bite already at the first level. At information sets $h_{6}$ to $h_{9}$, the voter learns precisely the policy points of both candidates. Every first level prudent rationalizable strategy must prescribe to vote for the candidate whose policy point is closest to his at any of those information sets. At the information set $h_{4}$, the voter is certain that $y^{a}=\frac{1}{4}$ and that $y^{b}$ is either $\frac{1}{4}$ or $\frac{3}{4}$. Any of his beliefs must assign some strict positive probability to $y^{b}=\frac{3}{4}$ since beliefs are full support. Thus, every first level rationalizable strategy must prescribe to vote for candidate $a$ at the information set $h_{4}$. A similar argument applies to $h_{2}$, and an analogous argument is used to show that the voter votes for candidate $b$ at information sets $h_{3}$ and $h_{5}$. However, 
at the information set $h_{1}$ the voter did not receive any non-trivial information about both candidates' policy points. Thus, there exist full support beliefs for which voting for $a$ is rational as well as a full support beliefs for which voting for $b$ is rational for the voter.

At the second level, candidates form full support beliefs on voter's first level rationalizable strategies and the opponent's strategies. In particular, candidate $a$, after the move of nature, $\left(\frac{1}{4}, \frac{1}{4}\right)$, knows now that when candidate $b$ reveals her policy point, $y^{b}=\frac{1}{4}$, the voter may or may not vote for her if she also truthfully reveals her policy point, $y^{a}=\frac{1}{4}$, while the voter votes for candidate $b$ if she does not. Candidate $a$ also knows that when candidate $b$ reveals trivial information, $Y$, the voter votes for her if she truthfully reveals her policy point, $y^{a}=\frac{1}{4}$, while the voter may or may not vote for her if she does not. Thus, any second level rationalizable strategy of candidate $a$ must prescribe revealing her policy point $y^{a}=\frac{1}{4}$ after history $\left(\frac{1}{4}, \frac{1}{4}\right)$. An analogous argument applies to history $\left(\frac{3}{4}, \frac{3}{4}\right)$. The difference is that now any prudent rationalizable strategy must prescribe no information, $Y$. At history $\left(\frac{1}{4}, \frac{3}{4}\right)$, candidate $a$ knows now that if she truthfully reveals her policy point the voter votes for her no matter how candidate $b$ acts. Otherwise, if she reveals trivial information, $Y$, then she may win or lose the election depending on whether candidate $b$ reveals and how the voter votes (she has full support beliefs over any of their strategies). Thus, any second level rationalizable strategy of candidate $a$ must prescribe revealing her policy point $y^{a}=\frac{1}{4}$ after history $\left(\frac{1}{4}, \frac{3}{4}\right)$. At history $\left(\frac{3}{4}, \frac{1}{4}\right)$, candidate $a$ knows that if she reveals her policy point, $y^{a}=\frac{3}{4}$, then no matter how candidate $b$ acts, the voter's first level rationalizable strategies prescribes voting for $b$. Yet, if candidate $a$ chooses to reveal trivial information, $Y$, then the voter may vote for her if candidate $b$ does reveal $Y$ either. Latter action is first level rationalizable for candidate $b$. Thus, any second level rationalizable strategy of candidate $a$ must prescribe $Y$ after history $\left(\frac{3}{4}, \frac{1}{4}\right)$. By analogous arguments, we can show that any second level rationalizable strategy of candidate $b$ can prescribe to reveal $y^{b}=\frac{1}{4}$ whenever his true policy point is $\frac{1}{4}$, while to reveal $Y$ with policy point $\frac{3}{4}$.

The iterated elimination process concludes after two levels of elimination. Table 1 summarizes the prudent rationalizable strategies for every player and every level. In order to quickly recognize any differences between strategies, we colored differing components. Although not all information is revealed at every second level rationalizable strategy profile, the voter's prudent rationalizable strategy is also optimal when he were to know all the information. 
Table 1: Prudent Rationalizable Strategies in the Uni-Dimensional Case

\begin{tabular}{|c||c|c|c|c|c|c|c|c|}
\hline & \multicolumn{7}{|c|}{ Voter } \\
\hline Information set & \multicolumn{5}{|c|}{$S_{v}^{1}=S_{v}^{2}$} \\
\hline \hline$h_{1}=\{(Y, Y)\}$ & $\mathrm{a}$ & $\mathrm{a}$ & $\mathrm{a}$ & $\mathrm{a}$ & $\mathrm{b}$ & $\mathrm{b}$ & $\mathrm{b}$ & $\mathrm{b}$ \\
$h_{2}=\left\{\left(Y, \frac{3}{4}\right)\right\}$ & $\mathrm{a}$ & $\mathrm{a}$ & $\mathrm{a}$ & $\mathrm{a}$ & $\mathrm{a}$ & $\mathrm{a}$ & $\mathrm{a}$ & $\mathrm{a}$ \\
$h_{3}=\left\{\left(Y, \frac{1}{4}\right)\right\}$ & $\mathrm{b}$ & $\mathrm{b}$ & $\mathrm{b}$ & $\mathrm{b}$ & $\mathrm{b}$ & $\mathrm{b}$ & $\mathrm{b}$ & $\mathrm{b}$ \\
$h_{4}=\left\{\left(\frac{1}{4}, Y\right)\right\}$ & $\mathrm{a}$ & $\mathrm{a}$ & $\mathrm{a}$ & $\mathrm{a}$ & $\mathrm{a}$ & $\mathrm{a}$ & $\mathrm{a}$ & $\mathrm{a}$ \\
$h_{5}=\left\{\left(\frac{3}{4}, Y\right)\right\}$ & $\mathrm{b}$ & $\mathrm{b}$ & $\mathrm{b}$ & $\mathrm{b}$ & $\mathrm{b}$ & $\mathrm{b}$ & $\mathrm{b}$ & $\mathrm{b}$ \\
$h_{6}=\left\{\left(\frac{1}{4}, \frac{1}{4}\right)\right\}$ & $\mathrm{a}$ & $\mathrm{a}$ & $\mathrm{b}$ & $\mathrm{b}$ & $\mathrm{a}$ & $\mathrm{a}$ & $\mathrm{b}$ & $\mathrm{b}$ \\
$h_{7}=\left\{\left(\frac{1}{4}, \frac{3}{4}\right)\right\}$ & $\mathrm{a}$ & $\mathrm{a}$ & $\mathrm{a}$ & $\mathrm{a}$ & $\mathrm{a}$ & $\mathrm{a}$ & $\mathrm{a}$ & $\mathrm{a}$ \\
$h_{8}=\left\{\left(\frac{3}{4}, \frac{1}{4}\right)\right\}$ & $\mathrm{b}$ & $\mathrm{b}$ & $\mathrm{b}$ & $\mathrm{b}$ & $\mathrm{b}$ & $\mathrm{b}$ & $\mathrm{b}$ & $\mathrm{b}$ \\
$h_{9}=\left\{\left(\frac{3}{4}, \frac{3}{4}\right)\right\}$ & $\mathrm{a}$ & $\mathrm{b}$ & $\mathrm{a}$ & $\mathrm{b}$ & $\mathrm{a}$ & $\mathrm{b}$ & $\mathrm{a}$ & $\mathrm{b}$ \\
\hline
\end{tabular}

\begin{tabular}{|c||c|c||c||c|c||c|}
\hline \multicolumn{1}{|c||}{} & \multicolumn{2}{c||}{ Candidate $a$} & \multicolumn{2}{c|}{ Candidate $b$} \\
\hline Information set & \multicolumn{2}{|c||}{$S_{a}^{1}$} & $S_{a}^{2}$ & $S_{b}^{1}$ & $S_{b}^{2}$ \\
\hline \hline$\left(\frac{1}{4}, \frac{1}{4}\right)$ & $\left\{\frac{1}{4}\right\}$ & $Y$ & $\left\{\frac{1}{4}\right\}$ & $\left\{\frac{1}{4}\right\}$ & $Y$ & $\left\{\frac{1}{4}\right\}$ \\
$\left(\frac{1}{4}, \frac{3}{4}\right)$ & $\left\{\frac{1}{4}\right\}$ & $Y$ & $\left\{\frac{1}{4}\right\}$ & $\left\{\frac{3}{4}\right\}$ & $Y$ & $Y$ \\
$\left(\frac{3}{4}, \frac{1}{4}\right)$ & $\left\{\frac{3}{4}\right\}$ & $Y$ & $Y$ & $\left\{\frac{1}{4}\right\}$ & $Y$ & $\left\{\frac{1}{4}\right\}$ \\
$\left(\frac{3}{4}, \frac{3}{4}\right)$ & $\left\{\frac{3}{4}\right\}$ & $Y$ & $Y$ & $\left\{\frac{3}{4}\right\}$ & $Y$ & $Y$ \\
\hline
\end{tabular}

\subsection{Two-Dimensional Case}

In the uni-dimensional case, the problem of unawareness of an issue does not come up since there is just one single default issue and the voter is aware of it. Would sufficient information be revealed if the voter may be unaware of an issue? To illustrate the answer to this question, we need a model with at least two issues. Again, issue 1 is the default issue. The most preferred policy point of a single voter in the two-dimensional space is $\left(\frac{5}{12}, \frac{2}{3}\right)$. The policy points of the candidates are elements of the set $Y=\left\{\left(\frac{1}{4}, \frac{1}{4}\right),\left(\frac{3}{4}, \frac{3}{4}\right)\right\}$. Note that the voter would vote for the candidate whose policy point is $\left(\frac{3}{4}, \frac{3}{4}\right)$ if he is aware of both issues, while he would vote for the candidate whose policy point is $\left.\frac{1}{4}\right|_{\{1\}}$ if he is aware of only the default issue.

The game form is depicted in Figure 2. Again, in order to save space, we truncate the trees after reaching the information sets of the voter. The lower tree is identical to Figure 1 since in this tree, the voter is unaware of the second dimension. The voter's 
information set at a node in the upper tree $T^{\{1,2\}}$, let's say after candidate $a$ and $b$ both choose $\left.\frac{1}{4}\right|_{\{1\}}$, is now in the lower tree $T^{\{1\}}$.

In the upper tree $T^{\{1,2\}}$, strategies of candidate $k$ prescribe to any profile of candidates' policy points $\left(y^{a}, y^{b}\right) \in Y \times Y$ actions in $\left\{\left\{y_{\left.\right|_{\{1\}} ^{k}}^{k}\right\}, Y_{\left.\right|_{\{1\}}},\left\{y^{k}\right\}, Y\right\}$. As the lower tree, $T^{\{1\}}$, depicts the uni-dimensional case, the set of $T^{\{1\}}$-partial strategies of candidate $k$ corresponds to her set of strategies in the uni-dimensional case. A strategy of the voter assigns to every information set (in both trees) the candidate for whom he votes.

The payoffs are analogous as before.

We now apply prudent rationalizability to the two-dimensional example. At each step of the iterative procedure, we have to consider information sets in both trees. At the first level, candidate $k$ has full support beliefs about any strategies of the other candidate and the voter. Similar to the uni-dimensional case, any strategy of candidate $k$ is first level rationalizable. Again, similar to the uni-dimensional case, for the voter prudent rationalizability has already some bite at the first level. Consider for instance the voter's information set $\left(Y_{\left.\right|_{\{1\}}},\left\{\left(\frac{1}{4}, \frac{1}{4}\right)\right\}\right)$. Since candidate $b$ reveals her policy point on both issues, the voter is aware of them, even though candidate $a$ reveals (trivial) information on issue 1 only. Because the voter has a full support belief, he must assign some strict positive probability on candidate $a$ having the policy point $\left(\frac{3}{4}, \frac{3}{4}\right)$, while he is certain that candidate $b$ has policy point $\left(\frac{1}{4}, \frac{1}{4}\right)$. Thus, any first level rationalizable strategy of the voter must prescribe voting for candidate $a$ at the information set $\left(Y_{\{1\}},\left\{\left(\frac{1}{4}, \frac{1}{4}\right)\right\}\right)$.

Table 2 shows the rationalizable strategies of the voter at each level of the iterative process. A strategy (i.e., column) assigns to each information set of the voter (i.e., row), the candidate for whom the voter votes. Note that at every level of the iterative process, the $T^{\{1\}}$-partial prudent rationalizable strategies (see the lower part of the table) correspond exactly to the prudent rationalizable strategies in the uni-dimensional case.

Consider now candidate $k$. At the second level of the iterative process, she forms full support beliefs about the first level rationalizable strategies of the voter and the other candidate. In particular, at the information set $\left(\left(\frac{3}{4}, \frac{3}{4}\right),\left(\frac{1}{4}, \frac{1}{4}\right)\right)$ candidate $a$ is now certain that the voter would vote for her if she reveals her policy point in the upmost tree. Otherwise, if she chooses to reveal some trivial information, e.g. $Y_{\left.\right|_{\{1\}}}$ or $Y$, then the voter may or may not vote for her depending on whether candidate $b$ reveals some non-trivial information. Moreover, if she reveals "true" policy point in the lower tree, then the voter may or may not voter for her depending on whether candidate $b$ raises issue 2 . Thus, any 
Figure 2: Two-dimensional example with uncertainty




Table 2: Prudent Rationalizable Strategies of the Voter in the Two-Dimensional Case

\begin{tabular}{|c|c|c|c|c|}
\hline \multirow{2}{*}{$\begin{array}{c}\text { Partial } \\
\text { Game } \\
\end{array}$} & \multicolumn{2}{|c|}{ Information Sets } & \multirow{2}{*}{\multicolumn{2}{|c|}{$S_{v}^{1}=S_{v}^{2}$}} \\
\hline & $a$ 's Action & $b$ 's Action & & \\
\hline$\overline{C T}^{\{1,2\}}$ & $Y_{\left.\right|_{\{1\}}}$ & $Y$ & $\mathrm{a}$ & $\mathrm{b}$ \\
\hline$T^{\{1,2\}}$ & $Y_{\left.\right|_{\{1\}}}$ & $\left\{\left(\frac{1}{4}, \frac{1}{4}\right)\right\}$ & $\mathrm{a}$ & $\mathrm{a}$ \\
\hline$T^{\{1,2\}}$ & $Y_{\left.\right|_{\{1\}}}$ & $\left\{\left(\frac{3}{4}, \frac{3}{4}\right)\right\}$ & $\mathrm{b}$ & $\mathrm{b}$ \\
\hline$T^{\{1,2\}}$ & $Y$ & $Y_{\{1\}}$ & $\mathrm{a}$ & b \\
\hline$T^{\{1,2\}}$ & $Y$ & $Y$ & $\mathrm{a}$ & b \\
\hline$T^{\{1,2\}}$ & $Y$ & $\left\{\frac{1}{4}\right\}_{\left.\right|_{\{1\}}}$ & $\mathrm{a}$ & a \\
\hline$T^{\{1,2\}}$ & $Y$ & $\left\{\left(\frac{1}{4}, \frac{1}{4}\right)\right\}$ & $\mathrm{a}$ & $\mathrm{a}$ \\
\hline$T^{\{1,2\}}$ & $Y$ & $\left\{\frac{3}{4}\right\}_{\left.\right|_{\{1\}}}$ & $\mathrm{b}$ & b \\
\hline$T^{\{1,2\}}$ & $Y$ & $\left\{\left(\frac{3}{4}, \frac{3}{4}\right)\right\}$ & $\mathrm{b}$ & $\mathrm{b}$ \\
\hline$T^{\{1,2\}}$ & $\left\{\frac{1}{4}\right\}_{\left.\right|_{\{1\}}}$ & $Y$ & $\mathrm{~b}$ & b \\
\hline$T^{\{1,2\}}$ & $\left\{\frac{1}{4}\right\}_{\left.\right|_{\{1\}}}$ & $\left\{\left(\frac{1}{4}, \frac{1}{4}\right)\right\}$ & $\mathrm{a}$ & b \\
\hline$T^{\{1,2\}}$ & $\left\{\frac{1}{4}\right\}_{\left.\right|_{\{1\}}}$ & $\left\{\left(\frac{3}{4}, \frac{3}{4}\right)\right\}$ & $\mathrm{b}$ & $\mathrm{b}$ \\
\hline$T^{\{1,2\}}$ & $\left\{\left(\frac{1}{4}, \frac{1}{4}\right)\right\}$ & $Y_{\{1\}}$ & $\mathrm{b}$ & $\mathrm{b}$ \\
\hline$T^{\{1,2\}}$ & $\left\{\left(\frac{1}{4}, \frac{1}{4}\right)\right\}$ & $Y$ & $\mathrm{~b}$ & $\mathrm{~b}$ \\
\hline$T^{\{1,2\}}$ & $\left\{\left(\frac{1}{4}, \frac{1}{4}\right)\right\}$ & $\left\{\frac{1}{4}\right\}_{\mid\{1\}}$ & $\mathrm{a}$ & b \\
\hline$T^{\{1,2\}}$ & $\left\{\left(\frac{1}{4}, \frac{1}{4}\right)\right\}$ & $\left\{\left(\frac{1}{4}, \frac{1}{4}\right)\right\}$ & $\mathrm{a}$ & b \\
\hline$T^{\{1,2\}}$ & $\left\{\left(\frac{1}{4}, \frac{1}{4}\right)\right\}$ & $\left\{\frac{3}{4}\right\}_{\{1\}}$ & $\mathrm{b}$ & b \\
\hline$T^{\{1,2\}}$ & $\left\{\left(\frac{1}{4}, \frac{1}{4}\right)\right\}$ & $\left\{\left(\frac{3}{4}, \frac{3}{4}\right)\right\}$ & $\mathrm{b}$ & $\mathrm{b}$ \\
\hline$T^{\{1,2\}}$ & $\left\{\frac{3}{4}\right\}_{\left.\right|_{\{1\}}}$ & $Y$ & $\mathrm{a}$ & $\mathrm{a}$ \\
\hline$T^{\{1,2\}}$ & $\left\{\frac{3}{4}\right\}_{\mid\{1\}}$ & $\left\{\left(\frac{1}{4}, \frac{1}{4}\right)\right\}$ & $\mathrm{a}$ & $\mathrm{a}$ \\
\hline$T^{\{1,2\}}$ & $\left\{\frac{3}{4}\right\}_{\left.\right|_{\{1\}}}$ & $\left\{\left(\frac{3}{4}, \frac{3}{4}\right)\right\}$ & a & b \\
\hline$T^{\{1,2\}}$ & $\left\{\left(\frac{3}{4}, \frac{3}{4}\right)\right\}$ & $Y_{\{1\}}$ & $\mathrm{a}$ & $\mathrm{a}$ \\
\hline$T^{\{1,2\}}$ & $\left\{\left(\frac{3}{4}, \frac{3}{4}\right)\right\}$ & $Y$ & $\mathrm{a}$ & $\mathrm{a}$ \\
\hline$T^{\{1,2\}}$ & $\left\{\left(\frac{3}{4}, \frac{3}{4}\right)\right\}$ & $\left\{\frac{1}{4}\right\}_{\left.\right|_{\{1\}}}$ & $\mathrm{a}$ & $\mathrm{a}$ \\
\hline$T^{\{1,2\}}$ & $\left\{\left(\frac{3}{4}, \frac{3}{4}\right)\right\}$ & $\left\{\left(\frac{1}{4}, \frac{1}{4}\right)\right\}$ & $\mathrm{a}$ & $\mathrm{a}$ \\
\hline$T^{\{1,2\}}$ & $\left\{\left(\frac{3}{4}, \frac{3}{4}\right)\right\}$ & $\left\{\frac{3}{4}\right\}_{\left.\right|_{\{1\}}}$ & $\mathrm{a}$ & b \\
\hline$T^{\{1,2\}}$ & $\left\{\left(\frac{3}{4}, \frac{3}{4}\right)\right\}$ & $\left\{\left(\frac{3}{4}, \frac{3}{4}\right)\right\}$ & $\mathrm{a}$ & b \\
\hline$T^{\{1\}}$ & $Y_{\left.\right|_{\{1\}}}$ & $Y_{\mid\{1\}}$ & a & b \\
\hline$T^{\{1\}}$ & $Y_{\mid\{1\}}$ & $\left\{\frac{1}{4}\right\}_{\left.\right|_{\{1\}}}$ & $\mathrm{b}$ & b \\
\hline$T^{\{1\}}$ & $\left\{\frac{1}{4}\right\}_{\left.\right|_{\{1\}}}$ & $Y_{\{1\}}$ & $\mathrm{a}$ & $\mathrm{a}$ \\
\hline$T^{\{1\}}$ & $Y_{\mid\{1\}}$ & $\left\{\frac{3}{4}\right\}_{\left.\right|_{\{1\}}}$ & $\mathrm{a}$ & $\mathrm{a}$ \\
\hline$T^{\{1\}}$ & $\left\{\frac{3}{4}\right\}_{\left.\right|_{\{1\}}}$ & $Y_{\mid\{1\}}$ & b & b \\
\hline$T^{\{1\}}$ & $\left\{\frac{1}{4}\right\}_{\mid\{1\}}$ & $\left\{\frac{1}{4}\right\}_{\left.\right|_{\{1\}}}$ & $\mathrm{a}$ & b \\
\hline$T^{\{1\}}$ & $\left\{\frac{1}{4}\right\}_{\mid\{1\}}$ & $\left\{\frac{3}{4}\right\}_{\left.\right|_{\{1\}}}$ & $\mathrm{a}$ & $\mathrm{a}$ \\
\hline$T^{\{1\}}$ & $\left\{\frac{3}{4}\right\}_{\left.\right|_{\{1\}}}$ & $\left\{\frac{1}{4}\right\}_{\left.\right|_{\{1\}}}$ & b & b \\
\hline$T^{\{1\}}$ & $\left\{\frac{3}{4}\right\}_{\left.\right|_{\{1\}}}$ & $\left\{\frac{3}{4}\right\}_{\left.\right|_{\{1\}}}$ & $\mathrm{a}$ & $\mathrm{b}$ \\
\hline
\end{tabular}


second level rationalizable strategy of candidate $a$ must reveal non-trivial information in the upmost tree about her policy point at the information set $\left(\left(\frac{3}{4}, \frac{3}{4}\right),\left(\frac{1}{4}, \frac{1}{4}\right)\right)$.

Table 3 presents the rationalizable strategies of the candidates at each level of the iterative process. Since the set of strategies that are remaining after each level of elimination is relatively large (i.e., for each candidate, 4096 strategies at the first level and 27 strategies at the second level), we just mention for each information set of the candidate the actions consistent with those strategies. Note again that at every level of the iterative process, the $T^{\{1\}}$-partial prudent rationalizable strategies (see the lower part of the table) correspond exactly to the prudent rationalizable strategies in the uni-dimensional case.

Table 3: Prudent Rationalizable Strategies of the Candidates in the Two-Dimensional Case

\begin{tabular}{|c||c|c||c|c|}
\hline \multicolumn{1}{|c||}{} & \multicolumn{2}{c||}{ Candidate $a$} & \multicolumn{2}{c|}{ Candidate $b$} \\
\hline $\begin{array}{c}\text { Information } \\
\text { Set }\end{array}$ & $\begin{array}{c}\text { Actions consistent } \\
\text { with } S_{a}^{1}\end{array}$ & $\begin{array}{c}\text { Actions consistent } \\
\text { with } S_{a}^{2}\end{array}$ & Actions consistent & Actions consistent \\
with $S_{b}^{2}$
\end{tabular}

As in the uni-dimensional case, the process stops after the second level. Although not all information is revealed in every second level rationalizable strategy profile, the voter's prudent rationalizable strategy is also optimal when he were fully aware and knew all the information. For instance, in some prudent rationalizable outcomes after the move of nature, $\left(\frac{3}{4}, \frac{3}{4}\right)$, the voter votes for candidate $a$, like at information set $\left(Y_{\left.\right|_{\{1\}}},\left\{\frac{3}{4}\right\}_{\mid\{1\}}\right)$; in others for $b$ like at information set $\left(Y_{\left.\right|_{\{1\}}},\left\{\left(\frac{3}{4}, \frac{3}{4}\right)\right\}\right)$; and at the other outcomes the voter may or may not vote for candidate $a$ like at information set $\left(\left\{\left(\frac{3}{4}, \frac{3}{4}\right)\right\},\left\{\left(\frac{3}{4}, \frac{3}{4}\right)\right\}\right)$. However, the voter's actions are optimal even with respect to full awareness of all political issues and complete information about the candidates' political positions. Compared to the unidimensional example, the two-dimensional example demonstrates that unawareness of an issues may not impede unraveling. This is due to the competition among candidates. Since candidates compete essentially in a zero-sum game, one or the other candidate has an incentive to raise an issue unless raising further issues cannot sway the election 
outcome. In Section 5.1 we show that competition is necessary for unraveling in the presence of unawareness, while we know from Grossman (1981), Milgrom (1981), and Milgrom and Roberts (1986) that it is not necessary in the case of full awareness.

\section{Main Results}

Despite voters' unawareness of issues and uncertainty about the candidates' policy points, we claim that electoral competition is sufficient for the emergence of election outcomes that are equivalent to outcomes with full awareness of issues and full information of policy points. Note that we do not claim that all the issues or all information are revealed during the campaign. All we claim is that the revelation of further issues and information won't change the election outcome.

Proposition 2 (Parliamentary Model) At every prudent rationalizable outcome of the parliamentary model with unawareness of political issues and incomplete information about candidates' policy points, if a voter votes for a candidate, then he prefers to vote for the same candidate when having full awareness of all political issues and complete information about the candidates' policy points. Conversely, if a voter strictly prefers to vote for a candidate under full awareness of political issues and complete information about candidates' policy points, then in any prudent rationalizable outcome of the parliamentary model with unawareness of political issues and incomplete information about candidates' policy points, he votes for the same candidate.

While the proof is naturally somewhat tedious due to the multiplicity of multidimensional policy spaces and the change of dimensions during the play, the basic idea is to show unraveling of sufficient issues and information such that election outcomes are the same as under full awareness and complete information. Roughly we show that with any first-level prudent rationalizable strategy, the voter who receives from exactly one candidate information that he has her most preferred policy point (in the policy space that she is aware of at that information set) must vote for that candidate. Any second-level prudent rationalizable strategy of candidates must be such that if the candidate has the best policy point for the voter in some subspace and all higher-dimensional spaces, then he must reveal it to the voter. For any $\ell \geq 1$, at level $(2 \ell+1)$ prudent rationalizable strategies voters vote for the candidate who reveals unambiguously the $\ell$-closest or any closer policy point to the voter, while at level $(2 \ell+2)$ prudent rationalizable strategies 
candidates reveal if possible to voters the $\ell$-closest or closer policy point in an appropriate policy space or any higher-dimensional policy space.

The presidential model is slightly more challenging than the parliamentary model since competing for a majority in the presidential model may involve less intense competition than competing for any small improvement in the share of voters in the parliamentary model. In the presidential model, all what a candidate cares about is a majority of voters while in the parliamentary model a candidate cares about every (even small) share of voters. In Section 5 we show that electoral competition is necessary for election outcomes under unawareness to be equivalent to election outcomes under full awareness. Yet, the positive result below shows that the electoral competition in presidential elections is sufficiently "intense".

Proposition 3 (Presidential Model) At every prudent rationalizable outcome of the presidential model with unawareness of political issues and incomplete information about candidates' policy points, if a candidate obtains the majority of votes then he could also obtain the majority of votes under full awareness of all political issues and complete information about the candidates' policy points. Conversely, if a majority of voters strictly prefer to vote for a particular candidate under full awareness of political issues and complete information about candidates' policy points, then in any prudent rationalizable outcome of the presidential model with unawareness of political issues and incomplete information about candidates' policy points, this candidate obtains a majority of votes.

The proofs of both results are contained in the appendix. In fact, we conveniently state the proofs in reverse order. We prove the result for the presidential model first and then show how the proof applies with minor modifications also to the parliamentary model. The proofs for the presidential and parliamentary model differ mainly in the set of "relevant" voters that candidates care about. In the parliamentary model, candidates care about every voter while in the presidential model candidates do not necessarily care about subsets of voters larger than a majority.

\section{Counterexamples}

In the previous section, we presented strong positive results on the efficiency of electoral competition with microtargeting of voters due to unraveling of awareness and information. 
One may question whether elections in the real world achieve unraveling. In this section, we like to shed some light on which assumptions if violated could prevent the revelation of "relevant" awareness and information. Identifying such assumptions we view as the main contribution of the model.

\subsection{Lack of Electoral Competition}

First, we show that electoral competition is necessary for the positive results to hold and that competition is the main driving force that allows for unraveling in the presence of unawareness while it is not necessary under full awareness. Milgrom and Roberts (1986) show that if there is one informed and one uninformed agent and the uninformed agent is "skeptical", then there is a sequential equilibrium with full unraveling of information (see also Grossman, 1981, and Milgrom, 1981). That is, competition may not be necessary for all the relevant information to be revealed in standard games with uncertainty only but no unawareness. Battigalli (2006) showed that sequential equilibrium can be replaced by a version of extensive-form rationalizability with a restriction on first-order conditional beliefs that requires "weak scepticism" in the sense that the lowest type consistent with a message has positive probability. Heifetz, Meier, and Schipper (2011b) show that the unraveling result can be obtained by replacing sequential equilibrium and "skepticism" of the uninformed agent by prudent rationalizablity, the solution concept also used in the current paper. ${ }^{18}$ That is, when the uninformed agent is aware of all issues but may be uncertain about the type of the sender, then full unraveling of the information obtains. Yet, Heifetz, Meier, and Schipper (2011b) also show that unraveling may break down in the presence of unawareness of the uninformed agent and a single sender. Here we will discuss a version of this example put in the context of elections in order to show that electoral competition is a necessary condition for our positive results to obtain under unawareness.

Consider an example where there is only one candidate (i.e., candidate $a$ only), hence

\footnotetext{
${ }^{18}$ There are advantages and disadvantages for using one or the other rationalizability procedure. Battigalli's (2006) solution has the nice property that it can be viewed as a reduction procedure on beliefs (that implies a reduction of strategies) while prudent rationalizability is necessarily a reduction procedure on strategies. Yet, prudent rationalizability is not "tailored" to the particular context with an extra restriction on first-order beliefs motivated by the application. It applies essentially to any finite game and for standard extensive-form games it is equivalent to iterated admissibility in the associated normal-form game (see Meier and Schipper, 2012).
} 
no electoral competition. In the introduction, we mentioned the example of elections in former East Germany. More generally, the example below may apply to any political environment with a "monopolist" party or an opposition that is not allowed to campaign. In such an "election" with a single candidate only, the candidate may provide more or less precise information about his political preferences on issues that should be considered by voters.

Figure 3: Failure of Unraveling in an Example with a Single Candidate

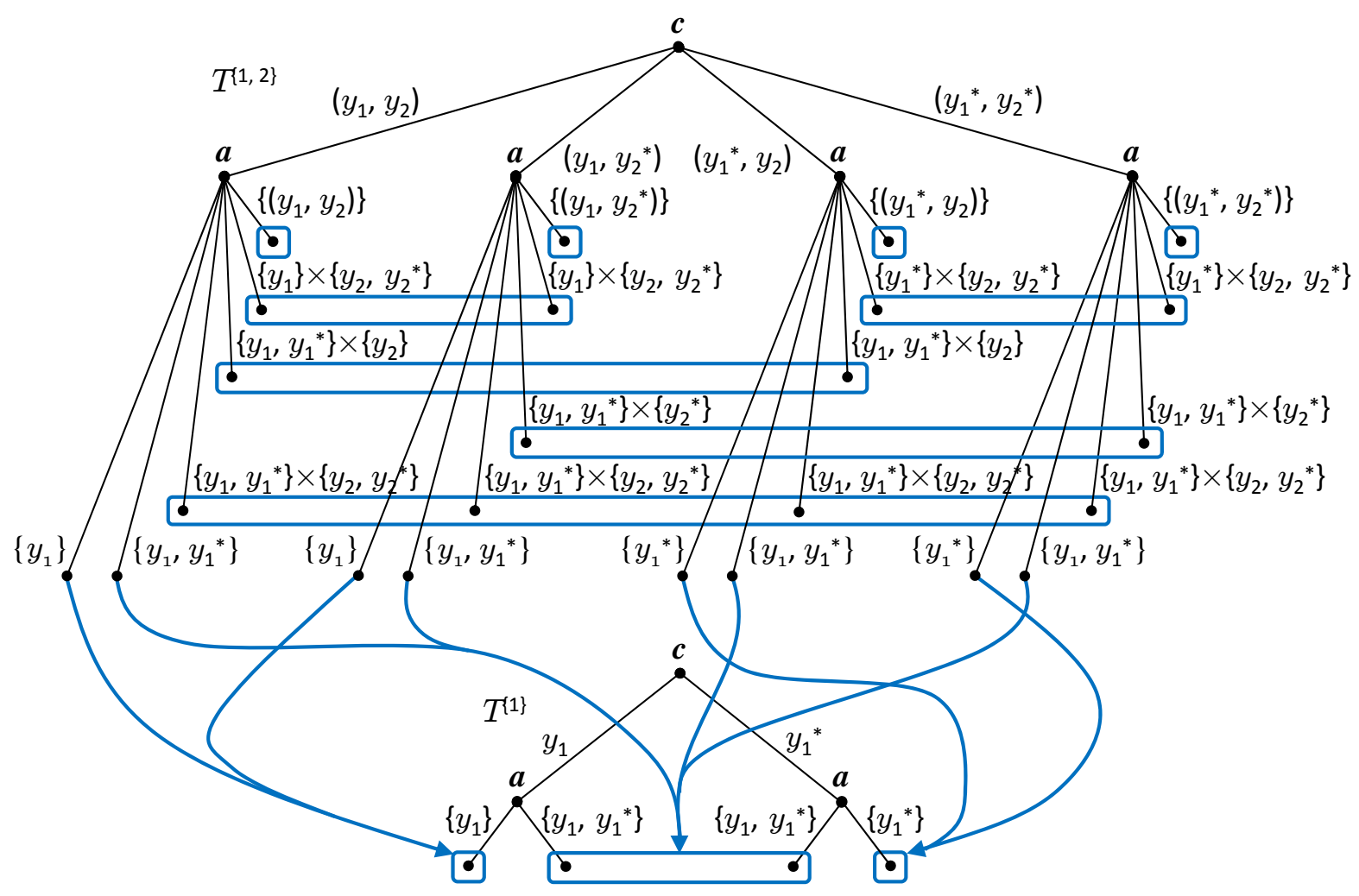

In our example, there are two issues. The policy point of the candidate is $y=\left(y_{1}, y_{2}\right)$, where $y_{1}$ and $y_{2}$ are the coordinates on issues 1 and 2 , respectively. If the candidate is not elected, a fixed "status quo" policy, $y^{*}=\left(y_{1}^{*}, y_{2}^{*}\right)$ is implemented instead, with $y_{i} \neq y_{i}^{*}$, $i \in\{1,2\}$. This "status quo" can be understood as the political position of the opposition who is not allowed to campaign. For simplicity, let there be a single voter only who is initially aware of default issue 1 only, i.e., the subspace $\left\{y_{1}, y_{1}^{*}\right\}$. The candidate can either reveal $\left\{y_{1}\right\}$ or $\left\{y_{1}, y_{1}^{*}\right\}$ on issue 1 , or $\{y\},\left\{y_{1}\right\} \times\left\{y_{2}, y_{2}^{*}\right\},\left\{y_{1}, y_{1}^{*}\right\} \times\left\{y_{2}\right\}$, or $\left\{y_{1}, y_{1}^{*}\right\} \times\left\{y_{2}, y_{2}^{*}\right\}$ on issues 1 and 2 . Once the candidate reveals anything on issue 2, the voter becomes aware of the entire policy space $\left\{y_{1}, y_{1}^{*}\right\} \times\left\{y_{2}, y_{2}^{*}\right\}$. Moreover, we assume that once he is aware of the entire policy space, he knows the status quo $y^{*}$ in 
the full-dimensional policy space. ${ }^{19}$ The game form is depicted in Figure 3. Again, to simplify the graphical exposition, we truncated the game form at the voter's information sets. The voter is assumed to strictly prefer $y_{1}$ to $y_{1}^{*}$ in uni-dimensional policy space but $y^{*}$ to $y$ in full-dimensional policy space. The candidate strictly prefers being appointed to not being appointed. If the candidate is not silent on issue 2 , then the voter must assign strict positive probability to $y$ and may not vote for the candidate, while the voter would appoint the candidate for sure if she reveals $\left\{y_{1}\right\}$ and keeps silent on issue 2 . Consequently, the candidate keeps silent on issue 2. Unraveling breaks down because the "status quo" is not actively campaigning with $y^{*}$. This example illustrates the electoral competition is crucial for unraveling to obtain under unawareness. But as we known from Grossman (1981), Milgrom (1981), and Milgrom and Roberts (1986) it is not crucial under full awareness and complete information. It highlights that unawareness of issues can be overcome with competition.

\subsection{Inability of Targeting Messages to Voters}

For our positive results, we assume that candidates are able to target different voters with different messages in terms of issues raised and the precision of information provided about their policy points. This feature is motivated by modern sophisticated campaign strategies that involve "microtargeting" of voters and "dog-whistle politics", and which appropriateness for election processes has been questioned in the political science literature (Hillygus and Shields, 2008). In this section we show that this is a crucial assumption for our positive results. This assumption is for example violated in a context in which candidates can campaign only on national TV, national radio, or nation-wide newspapers such that any information relayed to voters could reach any voter. Alternatively it may be violated in a situation in which candidates are prevented (either by law or by prohibitive costs) to gather and use information about individual voters to form sufficiently precise beliefs about their preferences.

In the following example, we will assume that each candidate cannot send different messages to different voters but must send the same message to all voters. Alternatively, we can interpret this as making public all campaign messages sent to voters. One can easily imagine a well-intentioned regulatory initiative that aims at maximal "transparency"

\footnotetext{
${ }^{19}$ Alternatively, we could assume that the opponent is not allowed to touch new issues on the campaign but can only provide information about his position on issues raised by the first candidate.
} 
of the election process and whose aim is to make all campaign information public to voters. We will show that such an initiative may be counterproductive in that the outcome may be the opposite to what it intends.

For simplicity, we ignore the issue of unawareness and show that microtargeting is already crucial with uncertainty only. There are three possible policy points of candidates, $y_{1}, y_{2}$, and $y_{3}$. Moreover, there are three voters. For simplicity we consider just three information sets of voters in Table 4 . The preferences of voters are such that their firstlevel prudent rationalizable strategies at those information sets are given in Table $4 .^{20}$ Voter 3 strictly prefers candidate $a$ with policy point $y_{1}$ no matter whether candidate $b$ 's

Table 4: First-Level Prudent Rationalizable Strategies of Voters

\begin{tabular}{|c|c||c|c||c|c||c||c|}
\hline \multicolumn{2}{|c||}{ Information Set } & \multicolumn{3}{c||}{ First-level Prud. Rat. Strategies } & Winning \\
Message by $a$ & Message by $b$ & \multicolumn{2}{c||}{ Voter 1} & Voter 2 & Voter 3 & Candidate \\
\hline$\left\{y_{1}\right\}$ & $\left\{y_{2}\right\}$ & $\mathrm{a}$ & $\mathrm{a}$ & $\mathrm{b}$ & $\mathrm{b}$ & $\mathrm{a}$ & $\mathrm{a}$ \\
$\left\{y_{1}\right\}$ & $\left\{y_{3}\right\}$ & $\mathrm{b}$ & $\mathrm{b}$ & $\mathrm{a}$ & $\mathrm{a}$ & $\mathrm{a}$ & $\mathrm{a}$ \\
$\left\{y_{1}\right\}$ & $\left\{y_{2}, y_{3}\right\}$ & $\mathrm{a}$ & $\mathrm{b}$ & $\mathrm{a}$ & $\mathrm{b}$ & $\mathrm{a}$ & $\mathrm{a}$ or $\mathrm{b}$ \\
\hline
\end{tabular}

policy point is $y_{2}$ or $y_{3}$. Voter 1 prefers candidate $a$ over candidate $b$ if the latter's policy point is $y_{2}$ while he prefers candidate $b$ over candidate $a$ if candidate $b$ 's policy point is $y_{3}$. Voter 2 has preferences dual to voter 1 . Consequently, when candidate $b$ reveals $\left\{y_{2}, y_{3}\right\}$, voters 1 and 2 have full-support beliefs that would make voting for candidate $a$ rational and full-support beliefs that would make voting for candidate $b$ rational.

Any second-level prudent rationalizable strategy of candidate $b$ must ascribe to reveal $\left\{y_{2}, y_{3}\right\}$ to all voters. Finally, with any third-level prudent rational belief, voters 1 and 2 cannot deduce anymore candidate $b$ 's policy point. For instance, voter 1 is uncertain whether candidate $b$ did not reveal $\left\{y_{2}\right\}$ because her policy point is in fact $\left\{y_{3}\right\}$ or because candidate $b$ 's policy point is indeed $\left\{y_{2}\right\}$ but she doesn't want to publicly reveal it because she would loose the election (i.e., the vote of voter 2).

This example turns out to be a special case of a more general aggregation paradox of the following kind: Consider a set of three outcomes $\{x, y, z\}$ and lotteries over those outcomes. There are three voters, each having a preference relation on lotteries over

\footnotetext{
${ }^{20}$ That is, voter 1 strictly prefers $y_{3}$ to $y_{1}$ to $y_{2}$ while voter 2 strictly prefers $y_{2}$ to $y_{1}$ to $y_{3}$. Voter 3 strictly prefers $y_{1}$ to any other policy points.
} 
outcomes as follows:

\begin{tabular}{|c|ccc|}
\hline Voter & \multicolumn{3}{|c|}{ Preferences } \\
\hline 1 & $(1,0,0) \succ_{1}(0,1,0)$ & $(1,0,0) \prec_{1}(0,0,1)$ & $(1,0,0) \prec_{1}\left(0, \frac{1}{2}, \frac{1}{2}\right)$ \\
2 & $(1,0,0) \prec_{2}(0,1,0)$ & $(1,0,0) \succ_{2}(0,0,1)$ & $(1,0,0) \prec_{2}\left(0, \frac{1}{2}, \frac{1}{2}\right)$ \\
3 & $(1,0,0) \succ_{3}(0,1,0)$ & $(1,0,0) \succ_{3}(0,0,1)$ & $(1,0,0) \succ_{3}\left(0, \frac{1}{2}, \frac{1}{2}\right)$ \\
\hline Majority & $(1,0,0) \succ_{M}(0,1,0)$ & $(1,0,0) \succ_{M}(0,0,1)$ & $(1,0,0) \prec_{M}\left(0, \frac{1}{2}, \frac{1}{2}\right)$ \\
\hline
\end{tabular}

Each voter's preference is consistent with von Neumann-Morgenstern utility. The last line of the table shows the "social choice" using simple majority over pairwise comparisons. Clearly, this social choice is inconsistent with von Neumann-Morgenstern utility.

\subsection{Lack of Political Reasoning Capabilities of Voters}

In our model we build a stark contrast between candidates and voters. Candidates are aware of all policy issues, know the preferences of voters, and are able to use sophisticated campaign strategies including microtargeting of voters. In contrast, voters are unaware of all policy issues except the default issue and don't know the preferences of candidates. The purpose for the stark contrast was to study whether electoral competition can overcome this stark asymmetry in awareness and information. Yet, we still assumed that voters are rational and use sophisticated political reasoning. In particular, our solution concept, prudent rationalizability, entails forward-induction reasoning by voters. One may question whether all voters are able to sophistically reason about political campaigns. What can we say about a context where voters' rationality is limited in the sense that they still try to do what is best for them but they are unable to use higher-order reasoning in the form of asking why this or that information and issue has been revealed by the candidate? That is, in this section we will assume that voters try to do what is best to them but are oblivious to the strategic intentions of candidates in that they do not necessarily believe that candidates are rational.

In the examples of Section 3, we obtained our strong unraveling result after just two levels of prudent rationalization. That is, essentially both voters as well as candidates are rational and believe both to be rational. We did not need to require that voters believe that candidates believe that voters are rational. It would be misleading however to conclude that just two levels of prudent rationalizability are required to obtain strong unraveling results in general. Both examples of Section 3 are special in that there are just two possible policy points that candidates could have. Consider now a policy space 
with three possible policy points of candidates, $Y=\left\{y_{1}, y_{2}, y_{3}\right\}$, no unawareness, and just a single voter who strictly prefers $y_{1}$ to $y_{2}$, and $y_{2}$ to $y_{3}$. Focus on the move of nature $\left(y^{a}, y^{b}\right)=\left(y_{2}, y_{3}\right)$. In Table 5 , the second column denotes all possible actions of candidate $a$ after this move of nature and the second row lists all possible actions of candidate $b$ after this move of nature. Thus, each cell corresponds to an information set of the voter. In each cell, we indicate the actions that first-level prudent rationalizable strategies of the voter can ascribe to this information set. Every second-level prudent rationalizable

Table 5: First-Level Prudent Rationalizable Actions for the Voter

\begin{tabular}{|c|c||c|c|c|c|}
\hline \multicolumn{2}{|c||}{} & \multicolumn{4}{c|}{ Information provided by candidate $b$} \\
\hline \multicolumn{2}{|c||}{} & $\left\{y_{3}\right\}$ & $\left\{y_{1}, y_{3}\right\}$ & $\left\{y_{2}, y_{3}\right\}$ & $Y$ \\
\hline \hline Information & $\left\{y_{2}\right\}$ & $a$ & $a, b$ & $a$ & $a, b$ \\
provided by & $\left\{y_{1}, y_{2}\right\}$ & $a$ & $a, b$ & $a$ & $a, b$ \\
candidate & $\left\{y_{2}, y_{3}\right\}$ & $a$ & $a, b$ & $a, b$ & $a, b$ \\
$a$ & $Y$ & $a$ & $a, b$ & $a, b$ & $a, b$ \\
\hline
\end{tabular}

strategy of a candidate prescribes to fully reveal its policy point if the policy point is $y_{1}$ and it never prescribes to fully reveal its policy point if it is $y_{3}$. Any second-level prudent rationalizable strategy of candidate $a$ may prescribe to reveal $\left\{y_{2}\right\},\left\{y_{1}, y_{2}\right\},\left\{y_{2}, y_{3}\right\}$, or $Y$ while any second-level prudent rationalizable strategy of candidate $b$ may prescribe to reveal $\left\{y_{1}, y_{3}\right\},\left\{y_{2}, y_{3}\right\}$, or $Y$. Assume that the voter has limited political reasoning capabilities in the sense that he does not form beliefs about the candidates' belief in the voter's rationality. That is, the voter won't necessary believe in the second-level prudent rationalizable strategies of candidates. In this case, the process of eliminating strategies stops after the second level. Note that there are many second-level prudent rationalizable outcomes where the voter votes for candidate $b$ even though he would prefer candidate $a$ over candidate $b$ under complete information. This is because not enough information is revealed after two levels of elimination of imprudent strategies.

It is possible albeit tedious to prove a more general result. For every finite level $\ell$ of eliminating imprudent strategies, there is a generic policy space (in the sense that the policy points of candidates could be perturbed slightly) with a sufficient large but finite number of possible policy points of candidates and a $\ell$-level prudent rationalizable election outcome that differs from the outcome under full awareness and complete information. Thus, the "richer" the policy space, the higher are the demands on the political reasoning capabilities of the voters in order for the unraveling results to obtain. We conclude that 
the political reasoning abilities of voters are very crucial for our results.

\section{Conclusion}

We analyzed a model of electoral competition with an extremely stark asymmetry of awareness and information between candidates and voters. Candidates are aware of all policy issues, know the preferences of voters, and are able to use sophisticated campaign strategies including microtargeting of voters. In contrast, voters are unaware of all policy issues except the default issue and don't know the preferences of candidates. The purpose for this extreme model of electoral competition is to study whether electoral competition can overcome this stark asymmetry in awareness and information. We show that despite the stark asymmetries in awareness and information, electoral competition both in the presidential and parliamentary model is strong enough to unravel all "relevant" awareness and information to voters in the sense that the election outcome corresponds to an election outcome under full awareness and complete information of voters. We show by an example that lack of competition impedes unraveling under unawareness of issues. Somewhat surprisingly, we found that microtargeting voters, a strategy whose appropriateness in elections has been questioned previously in the literature, facilitates the unraveling of information. Lack of sophisticated political reasoning about the intentions of candidates by voters may prevent unraveling of awareness and information.

We showed by example that if candidates are unable to target messages to voters, then not all relevant information and awareness may be revealed. Consequently, an indirect implication of our model is that voters should generally prefer a legislation that limits voter privacy. When voters' preferences become transparent to candidates and candidates can privately communicate with voters, then our unraveling results obtain. The indirect implication of happily giving up voter privacy goes against our intuition that it is valuable to preserve voters' privacy in terms of information and communication. Although our model leads us to acknowledge that both the privacy of voters and public political communication do not necessarily enhance electoral competition, we should keep in mind that our "indirect" predictions are made under the assumption of sophisticated political reasoning by voters. They may fail when voters are less sophisticated. ${ }^{21}$

\footnotetext{
${ }^{21}$ Concerns about privacy of voter records kept by campaigns have been voiced in the popular press. See for instance Tynan (2004) and Wayne (2000). Academic research on this topic appears to be scarce; for exceptions see van Onselen and Errington (2004) and Howard and Kreiss (2009).
} 
In Section 4 we illustrated that the candidates' ability to microtarget voters is crucial for our results. Essentially different (although not disjoint) information and awareness is provided to different voters. Wouldn't voters like to share their information with other voters and render microtargeting ineffective? Note that if voters know each others' preferences, they should like to share their own information with "like-minded" voters similar to viral campaigns in online social networks like Facebook or MySpace. They would have no interest to voluntarily provide their information to voters that are much different from them. That is, communication in social networks formed by like-minded voters is effectively enhancing microtargeting of voters. Lutz (2009), a public relations strategist, claims that Obama's formula of victory over McCain in the presidential election had to do with his 13 million member email-list and 3 million SMS and mobile subscribers, tools that McCain did not effectively use.

From the view point of the literature on unawareness, we have shown that unraveling of information in electoral competition is robust to voters' unawareness of political issues. It does not imply that unawareness "does not matter" since we show that unraveling under unawareness hinges crucially on the assumption of competition. We view it a strength of our framework that it enables us to formulate and analyze questions about the robustness of outcomes to unawareness. Our results are related to Heifetz, Meier, and Schipper (2011b) who show that unraveling of information about product quality may break down under unawareness in a model with a monopolist seller and a buyer. FilizOzbay (2011) shows in a different framework that a monopolist insurer may propose incomplete insurance contracts to an insuree who faces unawareness of some relevant contingencies but that competition among insurers leads to completeness. Li, Peitz, and Zhao (2011) study disclosure of product information to consumers under vertical competition in a duopoly when consumers may be unaware of one dimension of the product but otherwise have complete information. Our model and solution concept differs from theirs substantially. In particular, we allow for unawareness of many dimensions and incomplete information even after some dimensions have been disclosed. This requires us to model carefully the state of mind of (unaware) voters after candidates have made their disclosure decisions. On the other hand, Li, Peitz, and Zhao (2011) allow firms to also set prices and study the effect of timing price and disclosure decisions.

We are not the first who discuss salience of issues in electoral competition. There is a large literature in political science on issue ownership theory starting with Budge and Farlie (1983) and Petrocik (1996). According to issue ownership theory, "candidates 
emphasize issues on which they are advantaged". Yet, as Green and Hobolt (2008) emphasize with data from British elections, as parties converge ideologically, their relative competence on an issue becomes more important than ideological considerations. At a first glance, a candidate's relative competence on an issue as reason for the candidate to campaign on that issue seems different from our model. Yet, if political positions in our model are reinterpreted as degrees competence on the issues, our model becomes a formal model of issue ownership theory. Presumably in such a setting voters prefer uniformly more competence to less, and hence preferences of voters are homogeneous. Our model predicts then that enough relevant issues and information on the candidates's competence is revealed in electoral competition such that election outcomes are identical to the ones under full awareness of all issues and complete information about the candidates' competence. Note that such a result would not hinge anymore on the candidates' abilities to microtarget voters as all voters have homogeneous preferences over competence. Yet, a lack of electoral competition may still prevent unraveling under unawareness of issues because the candidate could be silent on issues he does not "own".

In economics, Berliant and Konishi (2005) study whether candidates in a multidimensional Downs model with linear utility of voters like to announce policies on all issues. They assume that voters know the state of the world and candidates just have a prior distribution over voters' types. They show that if a Nash equilibrium exists, candidates like to announce policies on all issues. Moreover, they show by example that non-salience may emerge when candidates face Knightian uncertainty and maximize minimal expected utility. Our models differ substantially from each other. Besides differing assumptions about ideological versus opportunistic candidates and differing informational assumptions, it is impossible in their model to be salient on an issue without announcing a policy on this issue. There is also no role for microtargeting of voters. Moreover, our focus on a rationalizablity procedure rather than Nash equilibrium allows us to shed more light on the importance of political reasoning capabilities of voters. Colomer and Llavador (2012) study electoral competition with salience of issues. Ex ante salience of an issue is proportional to the disagreement of the electorate about the status quo policy of the incumbent on this issue. The ex post salience of an issue is highest when both candidates campaign on it by choosing a policy point. Candidates are allowed to campaign only on one issue each. They show that in subgame perfect equilibrium candidates may not campaign on the ex ante most salient issues if there is no policy on this issue that would attract broad agreement among the electorate. Again, our model differs substan- 
tially from theirs. Most importantly, in our model candidates can choose to campaign on as many issues as they like and can target different issues to different voters.

Our work is related to the large literature on information aggregation of elections. McKelvey and Ordeshook (1985) present an uni-dimensional Down model with two candidates. Candidates do not know the preferences of voters and uninformed voters do not know the political positions adopted by candidates but there is also a share of informed voters who know the political positions. All participants can learn from "polls" and "interest group endorsements". They show that in a version of self-confirming equilibrium, in which strategies of participants are optimal with respect to the public information available and the public information is consistent with the strategies of participants, election outcomes correspond to full information election outcomes. McKelvey and Ordeshook (1987) present sufficient conditions on the number and distribution of informed and uninformed voters for an analogous result in a multi-dimensional setting, in which poll-data must be broken down by subgroups of voters. Feddersen and Pesendorfer (1997) show that large elections with strategic voters and two fixed policy alternatives can aggregate information about a uni-dimensional state variable. Voters are differently informed by some "information services" instead by strategically campaigning candidates. They also show that with higher-dimensional uncertainty, elections may not effectively aggregate information and suggest that future research should "focus on the events that precede elections - nominating procedures, campaigns, polls, etc. - as such events determine the information environment." Although our model is very different from aforementioned models, it can viewed as focusing exactly on "events that precede elections". Gratton (2011) studies electoral competition between two perfectly informed candidates that are faced by voters who have a common value over the policies but he requires them to have some information about what is best for them. Candidates can be of two types, either strategic or truthful. He studies a sequential equilibrium that also entails some forwardinduction in that voters can revise beliefs when candidates propose different policies and that leads an election outcome identical to the full information outcome. Heidhues and Lagerlöf (2003) study a model in which voters possess no information. But candidates receive imperfectly correlated private signals about the state of nature. In equilibrium candidates bias their information transmission through the choice of platforms towards the voters' prior, letting information revelation fail. Laslier and van der Straeten (2004) show that this conclusion is not robust as soon as the voters have a tiny bit of relevant information. In this case, all equilibria are dismissed by standard refinements except the 
one in which information revelation occurs.

Finally, we are not aware of models of electoral campaigning with microtargeting of voters. Most closely related is Glaezer, Ponzetto, and Shapiro (2005) who study electoral competition à la Downs (1957) but with endogenous voter turnout in which some party members can observe secretly the platform of the candidate on "their side" of the political spectrum while less members of the other parties can observe it. Thus deviating from the median voter does not necessarily alienate voters on the other side while mobilizing support on its own side producing divergent platforms. Different from our model, there is no role for parties to microtarget "swing voters" that may be traditionally associated with the other party.

\section{A Proofs}

\section{A.1 Proof of Proposition 3}

Consider first the case in which there is a majority of voters who are indifferent between candidates when all voters are fully aware and have complete information about the candidates' profile of policy points $\left(y^{a}, y^{b}\right) \in Y \times Y$ in the full-dimensional policy space. For those voters, it is rational to vote for any candidate. Hence, for those voters it is trivially true that if any of them prefers to vote for a particular candidate in a prudent rationalizable outcome of the presidential model with unawareness of political issues and incomplete information about candidates' policy points, then he prefers to vote for the same candidate when having full awareness of all political issues and complete information about the candidates' policy points. Thus, from now on we consider only the case in which there is no majority of voters who are indifferent between the candidates when all voters have full awareness of political issues and complete information about candidates' policy points. $^{22}$

We also assume $|N| \geq 2$ since otherwise the presidential model is a special case of the parliamentary model.

The proof proceeds by induction.

\footnotetext{
${ }^{22}$ Note that it does not imply that there is no majority of voters who are indifferent between candidates under unawareness of some issues but complete information about the policy points in the subspace of issues that they are aware of.
} 
First level: For any candidate $k \in\{a, b\}$ we have $S_{k}^{1}=S_{k}$. For candidate $k$, every $s_{k} \in S_{k}$ is first-level rationalizable with a belief system $\beta_{k}$ such that for every information set $h_{k}$ the full-support belief $\beta_{k}\left(h_{k}\right)$ puts sufficiently high probability to strategies of voter $j$ that ascribe voting for $k$ at every information set reached by $s_{k}\left(h_{k}\right)$ and voting for $-k$ at all other information sets of $j$, for all $j \in N$.

Before we turn to first-level prudent rationalizable strategies of voters, it will be helpful to introduce the following notation. We say that $y^{k}$ reaches the information set $h_{j}$ of voter $j$ if there is a move of nature $\left(y^{k}, y^{-k}\right)$ and a strategy profile of candidates $\left(s_{k}, s_{-k}\right)$ such that there is a path (i.e., a sequence of nodes) from $\left(y^{k}, y^{-k}\right)$ to some node in $h_{j}$. Let $Y^{k}\left(h_{j}\right):=\left\{y^{k} \in Y_{I_{I\left(h_{j}\right)}}: y^{k}\right.$ reaches $\left.h_{j}\right\}$. That is, $Y^{k}\left(h_{j}\right)$ is the set of candidate's policy points in $Y_{\left.\right|_{I\left(h_{j}\right)}}$ that voter $j$ considers possible at his information set $h_{j}$.

For any voter $j$ and any of his information sets $h_{j} \in H_{j}$, define inductively,

$$
Y_{j}^{(1), I\left(h_{j}\right)}:=\left\{y \in Y_{\left.\right|_{I\left(h_{j}\right)}}:\left\|x^{j}-y\right\|_{I\left(h_{j}\right)} \leq\left\|x^{j}-y^{\prime}\right\|_{I\left(h_{j}\right)} \text { for all } y^{\prime} \in Y_{I_{I\left(h_{j}\right)}}\right\}
$$

and for $\ell>1$,

$Y_{j}^{(\ell), I\left(h_{j}\right)}:=\left\{y \in Y_{\left.\right|_{I\left(h_{j}\right)}} \backslash\left(\bigcup_{\ell^{\prime} \leq \ell-1} Y_{j}^{\left(\ell^{\prime}\right), I\left(h_{j}\right)}\right): \begin{array}{l}\left\|x^{j}-y\right\|_{I\left(h_{j}\right)} \leq\left\|x^{j}-y^{\prime}\right\|_{I\left(h_{j}\right)} \\ \text { for all } y^{\prime} \in Y_{I_{I\left(h_{j}\right)}} \backslash\left(\bigcup_{\ell^{\prime} \leq \ell-1} Y_{j}^{\left(\ell^{\prime}\right), I\left(h_{j}\right)}\right.\end{array}\right)$.

That is, $Y_{j}^{(1), I\left(h_{j}\right)}$ is the set of voter $j$ 's most preferred candidates' policy points in the policy space that he is aware of at the information set $h_{j}$. Similarly, $Y_{j}^{(\ell), I\left(h_{j}\right)}$ is the set of voter $j$ 's $\ell$-most preferred candidates' policy points in the policy space that he is aware of at his information set $h_{j}$. Since $Y$ is finite, there is a unique set of voter $j$ 's least preferred candidates' policy points that he is aware of at his information set $h_{j}$, i.e., a largest $\ell$.

With these definitions in place, we turn to the first-level prudent rationalizable strategies of voters. For any voter $j$ consider an information set $h_{j}$ with $Y^{k}\left(h_{j}\right) \subseteq Y_{j}^{(1), I\left(h_{j}\right)}$ and $Y^{-k}\left(h_{j}\right) \nsubseteq Y_{j}^{(1), I\left(h_{j}\right)}$. Note that for any of voter $j$ 's belief system $\beta_{j}$, the support of $\beta_{j}\left(h_{j}\right)$ is the set of policy points and strategy profiles of candidates that reach the information set $h_{j}$. With any such a belief system, any first level prudent rationalizable strategy of voter $j$ must ascribe voting for candidate $k$ at $h_{j}$. This is because with any such belief system, voter $j$ is certain that candidate $k$ has his most preferred policy point in $Y_{\left.\right|_{I\left(h_{j}\right)}}$ while he must assign some strict positive probability to policy points of candidate $-k$ 
that are strictly less preferred..$^{23}$

Second level: Before we turn to second-level rationalizable strategies, the following definition will be helpful for the proof. Given an information set $h_{k}$ of candidate $k$ reached by the move of nature $\left(r_{I\left(h_{k}\right)}^{I}\left(y^{k}\right), r_{I\left(h_{k}\right)}^{I}\left(y^{-k}\right)\right)$, let for any $\ell \geq 1, N_{k}^{(\ell)}\left(h_{k}\right) \subseteq N$ be a (possibly empty) subset of voters such that

(N1) every voter $j \in N_{k}^{(\ell)}\left(h_{k}\right)$ strictly prefers $r_{I\left(h_{k}\right)}^{I}\left(y^{k}\right)$ over $r_{I\left(h_{k}\right)}^{I}\left(y^{-k}\right)$,

(N2) for every voter $j \in N_{k}^{(\ell)}\left(h_{k}\right), r_{I\left(h_{k}\right)}^{I}\left(y^{k}\right) \in Y_{j}^{\left(\ell^{\prime}\right), I\left(h_{k}\right)}$ for some $\ell^{\prime}$ with $\ell \geq \ell^{\prime} \geq 1$,

(N3) the cardinality of $N_{k}^{(\ell)}\left(h_{k}\right)$ is such that ${ }^{24}$

$$
\left|N_{k}^{(\ell)}\left(h_{k}\right)\right| \leq\left\{\begin{array}{cl}
\left\lceil\frac{1}{2}|N|\right\rceil & \text { if } k=a \text { or }(k=b \text { and }|N| \text { is odd) } \\
\frac{1}{2}|N|+1 & \text { else (i.e., if } k=b \text { and }|N| \text { is even) }
\end{array}\right.
$$

(N4) if $\left|N_{k}^{(\ell)}\left(h_{k}\right)\right| \leq \frac{1}{2}|N|$ then there is no $N^{\prime} \subseteq N$ that satisfies properties N1 to N3 in place of $N_{k}^{(\ell)}\left(h_{k}\right)$ and for which $\left|N^{\prime}\right|>\left|N_{k}^{(\ell)}\left(h_{k}\right)\right|$.

We claim that if $s_{k}$ is a second-level prudent rationalizable strategy of candidate $k \in\{a, b\}$ then for any information set $h_{k}$ of candidate $k$ reached by the move of nature $\left(r_{I\left(h_{k}\right)}^{I}\left(y^{k}\right), r_{I\left(h_{k}\right)}^{I}\left(y^{-k}\right)\right)$ we have that for any voter $j \in N,\left(s_{k}\left(h_{k}\right)\right)_{j} \subseteq Y_{I^{j}}$ for some $I^{j} \subseteq I\left(h_{k}\right)$. Moreover, there is (a possibly empty) subset of voters $N_{k}^{(1)}\left(h_{k}\right) \subseteq N$ such that for all $j \in N_{k}^{(1)}\left(h_{k}\right)$ and any $I^{\prime}$ with $I^{j} \subseteq I^{\prime} \subseteq I\left(h_{k}\right)$,

(i) $\left(r_{I^{j}}^{I^{\prime}}\right)^{-1}\left(\left(s_{k}\left(h_{k}\right)\right)_{j}\right) \subseteq Y_{j}^{(1), I^{\prime}}$, and

(ii) voter $j$ strictly prefers $r_{I^{\prime}}^{I}\left(y^{k}\right)$ over $r_{I^{\prime}}^{I}\left(y^{-k}\right)$.

We show that these conditions are necessary for second-level prudent rationalizable strategies of candidates. Consider any information set $h_{k}$ of candidate $k$ such that $k$ knows $\left(r_{I\left(h_{k}\right)}^{I}\left(y^{k}\right), r_{I\left(h_{k}\right)}^{I}\left(y^{-k}\right)\right)$. Let $s_{k}$ be a second-level prudent rationalizable strategy of candidate $k \in\{a, b\}$. By the definition of strategy, we must have that for any $j \in N$, $\left(s_{k}\left(h_{k}\right)\right)_{j} \subseteq Y_{I^{j}}$ for some $I^{j} \subseteq I\left(h_{k}\right)$. Suppose to the contrary that for every $N_{k}^{(1)}\left(h_{k}\right)$ there is a nonempty subset of voters $N^{\prime} \subseteq N_{k}^{(1)}\left(h_{k}\right)$ such that for any $j \in N^{\prime}$ properties

\footnotetext{
${ }^{23}$ This condition is just a necessary condition for first-level prudent rationalizable strategies of voters.

${ }^{24}$ Recall from Section 2 that $a$ wins if it obtains weakly more than half of the votes, whereas $b$ wins with strictly more than half of the votes. $\lceil x\rceil$ denotes the smallest integer not less than $x$.
} 
(i) or (ii) are violated. (If $N_{k}^{(1)}\left(h_{k}\right)$ is empty, there is nothing to prove.) That is, for any $j \in N^{\prime}$, there exists $\tilde{I}^{j}$ with $I^{j} \subseteq \tilde{I}^{j} \subseteq I\left(h_{k}\right)$ such that $\left(r_{I^{j}}^{\tilde{I}^{j}}\right)^{-1}\left(\left(s_{k}\left(h_{k}\right)\right)_{j}\right) \nsubseteq Y_{j}^{(1), \tilde{I}^{j}}$ or $j$ does not strictly prefer $r_{\tilde{I}^{j}}^{I}\left(y^{k}\right)$ over $r_{\tilde{I}^{j}}^{I}\left(y^{-k}\right)$.

With any belief system $\beta_{k} \in B_{k}^{2}$, candidate $k$ at $h_{k}$ must assign strict positive probability to strategies of candidate $-k$ that reveal information to any voter $j \in N^{\prime}$ such that an information set $h_{j}$ of voter $j \in N^{\prime}$ in $T^{\tilde{I}^{j}}$ is reached with $Y^{-k}\left(h_{j}\right) \cap Y_{j}^{(1), \tilde{I}^{j}} \neq \emptyset$.

Let $\bar{N} \subset N$ such that $N_{k}^{(1)}\left(h_{k}\right) \subseteq \bar{N}$ and

$$
|\bar{N}|=\left\{\begin{array}{cl}
\left\lceil\frac{1}{2}|N|\right\rceil & \text { if } k=a \text { or (if } k=b \text { and }|N| \text { is odd) } \\
\frac{1}{2}|N|+1 & \text { else (i.e., if } k=b \text { and }|N| \text { is even). }
\end{array}\right.
$$

We can partition the set of voters $N$ into $\left\{N_{k}^{(1)}\left(h_{k}\right) \backslash N^{\prime}, N^{\prime}, \bar{N} \backslash N_{k}^{(1)}\left(h_{k}\right), N \backslash \bar{N}\right\}$. With any belief system $\beta_{k} \in B_{k}^{2}$, candidate $k$ at $h_{k}$ must assign strict positive probability to first-level prudent rationalizable strategies of voter $j$ such that

$$
\text { if } j \in\left\{\begin{array}{ll}
N_{k}^{(1)}\left(h_{k}\right) \backslash N^{\prime} & \text { then } j \text { votes for } k \\
N^{\prime} & \text { then } j \text { votes for }-k \\
\bar{N} \backslash N_{k}^{(1)}\left(h_{k}\right) & \text { then } j \text { votes for } k \\
N \backslash \bar{N} & \text { then } j \text { votes for }-k
\end{array},\right.
$$

which implies that candidate $k$ must assign strictly positive probability to $-k$ winning the election. Yet, candidate $k$ can strictly improve his expected payoff at $h_{k}$ given $\beta_{k}\left(h_{k}\right)$ by replacing $\left(s_{k}\left(h_{k}\right)\right)_{j}$ for $j \in N^{\prime}$ with $\left\{r_{I\left(h_{k}\right)}^{I}\left(y^{k}\right)\right\}$, because at any information set $h_{j}$ of voter $j \in N^{\prime}$ reached by this modified strategy of candidate $k$, any first-level prudent rationalizable strategy of voters $j \in N^{\prime}$ must ascribe voting for $k$ implying that $k$ wins the election, a contradiction.

For all voters $j \in N, S_{j}^{2}=S_{j}^{1}$ since $S_{k}^{1}=S_{k}$ for $k \in\{a, b\}$.

Induction step: The following definitions are helpful. For any $\ell>1$, we say that strategy $s_{j}$ of voter $j$ satisfies condition $\ell$ if for every $h_{j}$ such that for some $k \in\{a, b\}$,

1. for some $\ell^{k}$ with $\ell \geq \ell^{k} \geq 1, Y^{k}\left(h_{j}\right) \cap Y_{j}^{\left(\ell^{k}\right), I\left(h_{j}\right)} \neq \emptyset$ and $Y^{k}\left(h_{j}\right) \cap Y_{j}^{\left(\ell^{\prime}\right), I\left(h_{j}\right)}=\emptyset$ for all $\ell^{\prime}>\ell^{k}$, and

2. if for some $\ell^{-k}$ with $\ell \geq \ell^{-k} \geq 1, Y^{-k}\left(h_{j}\right) \cap Y_{j}^{\left(\ell^{-k}\right), I\left(h_{j}\right)} \neq \emptyset$ and $Y^{-k}\left(h_{j}\right) \cap Y_{j}^{\left(\ell^{\prime \prime}\right), I\left(h_{j}\right)}=$ $\emptyset$ for all $\ell^{\prime \prime}>\ell^{-k}$, then $\ell^{-k}>\ell^{k}$,

then voter $j$ votes for $k$ at $h_{j}$. Intuitively, this conditions states that if candidate $k$ reveals information to voter $j$ that is weakly better than her $\ell$-most preferred policy points and 
$-k$ reveals information to voter $j$ that is not unambiguously better than $k$ 's information, then voter $j$ votes for candidate $k$.

For any $\ell>1$, we say that strategy $s_{k}$ of candidate $k$ satisfies condition $\ell$ if for every $y^{k} \in Y$ and every information set $h_{k}$ of candidate $k$ reached by the move of nature $\left(r_{I\left(h_{k}\right)}^{I}\left(y^{k}\right), r_{I\left(h_{k}\right)}^{I}\left(y^{-k}\right)\right)$ we have that for all voters $j \in N,\left(s_{k}\left(h_{k}\right)\right)_{j} \subseteq Y_{I_{I^{j}}}$ for some $I^{j} \subseteq I\left(h_{k}\right)$. Moreover, there is (a possibly empty) subset of voters $N_{k}^{(\ell)}\left(h_{k}\right) \subseteq N$ such that for all $j \in N_{k}^{(\ell)}\left(h_{k}\right)$ and any $I^{\prime}$ with $I^{j} \subseteq I^{\prime} \subseteq I\left(h_{k}\right)$,

(I) there is $\ell^{I^{\prime}}$ with $\ell \geq \ell^{I^{\prime}} \geq 1$ such that $r_{I^{\prime}}^{I^{\prime}}\left(y^{k}\right) \in Y_{j}^{\left(\ell^{I^{\prime}}\right), I^{\prime}}$ (and hence $\left(r_{I^{j}}^{I^{\prime}}\right)^{-1}\left(\left(s_{k}\left(h_{k}\right)\right)_{j}\right) \cap$ $\left.Y_{j}^{\left(\ell^{I^{\prime}}\right), I^{\prime}} \neq \emptyset\right)$ and $\left(r_{I^{j}}^{I^{\prime}}\right)^{-1}\left(\left(s_{k}\left(h_{k}\right)_{j}\right) \cap Y_{j}^{\left(\ell^{\prime}\right), I^{\prime}}=\emptyset\right.$ for all $\ell^{\prime}$ such that $\ell^{\prime}>\ell^{I^{\prime}}$, and

(II) voter $j$ strictly prefers $r_{I^{\prime}}^{I}\left(y^{k}\right)$ over $r_{I^{\prime}}^{I}\left(y^{-k}\right)$.

Assume now that we have proved that for every voter $j \in N$ the $(2 \ell-1)$-level prudent rationalizable strategies of voter $j$ satisfy condition $\ell$ and that for every candidate $k \in\{a, b\}$ the $2 \ell$-level prudent rationalizable strategies of candidate $k$ satisfy condition $\ell$. We claim that for any voter $j \in N$, the $(2 \ell+1)$-level prudent rationalizable strategies satisfy condition $\ell+1$ and for every candidate $k \in\{a, b\}$, the $(2 \ell+2)$-level prudent rationalizable strategies of candidate $k$ satisfy condition $\ell+1$.

Consider a voter $j \in N$ with information set $h_{j}$. Suppose that for some $\ell^{k}$ with $\ell+1 \geq \ell^{k} \geq 1, Y^{k}\left(h_{j}\right) \cap Y_{j}^{\left(\ell^{k}\right), I\left(h_{j}\right)} \neq \emptyset$ and $Y^{k}\left(h_{j}\right) \cap Y_{j}^{\left(\ell^{\prime}\right), I\left(h_{j}\right)}=\emptyset$, for all $\ell^{\prime}$ with $\ell^{\prime}>\ell^{k}$. Unless we also have that for some $\ell^{-k}$ with $\ell^{k} \geq \ell^{-k} \geq 1, Y^{-k}\left(h_{j}\right) \cap Y_{j}^{\left(\ell^{-k}\right), I\left(h_{j}\right)} \neq \emptyset$ and $Y^{-k}\left(h_{j}\right) \cap Y_{j}^{\left(\ell^{\prime \prime}\right), I\left(h_{j}\right)}=\emptyset$, for all $\ell^{\prime \prime}$ with $\ell^{\prime \prime}>\ell^{-k}$, then with any $2 \ell+1$ prudent rationalizable strategy, voter $j$ must vote for $k$ at $h_{j}$. To see this note that for any belief system of voter $j, \beta_{j} \in B_{j}^{2 \ell+1}$, the support of the belief $\beta_{j}\left(h_{j}\right)$ at $h_{j}$ is the set of $2 \ell$-prudent rationalizable strategies of candidates who by assumption satisfy condition $\ell$. Thus, the voter is certain at $h_{j}$ of $y_{\left.\right|_{\left(h_{j}\right)} ^{k}}^{k} \in Y_{j}^{\left(\ell^{k}\right), I\left(h_{j}\right)}$. Moreover, since candidates' strategies satisfy condition $\ell$, voter $j$ with belief $\beta_{j}\left(h_{j}\right)$ cannot assign strict positive probability to policy points $y_{\mid{ }_{I\left(h_{j}\right)}}^{-k}$ of candidate $-k$ that are strictly preferred to $k$ 's policy point since otherwise $-k$ would have revealed it. It follows that voter $j$ 's $(2 \ell+1)$-level prudent rationalizable strategies satisfy condition $\ell+1$.

Consider any information set $h_{k}$ of candidate $k$ such that $k$ knows $\left(r_{I\left(h_{k}\right)}^{I}\left(y^{k}\right), r_{I\left(h_{k}\right)}^{I}\left(y^{-k}\right)\right)$. Let $s_{k}$ be a $(2 \ell+2)$-level prudent rationalizable strategy of candidate $k$. By the definition of strategy, we must have that for any $j \in N,\left(s_{k}\left(h_{k}\right)\right)_{j} \subseteq Y_{\left.\right|_{I}}$ for some $I^{j} \subseteq I\left(h_{k}\right)$. Suppose to the contrary that for every $N_{k}^{(\ell+1)}\left(h_{k}\right)$ there is a nonempty subset of voters, 
$N^{\prime} \subseteq N_{k}^{(\ell+1)}\left(h_{k}\right)$, such that for any $j \in N^{\prime}$ there exists $\tilde{I}^{j}$ with $I^{j} \subseteq \tilde{I}^{j} \subseteq I\left(h_{k}\right)$ for which properties (I) or (II) are violated. (If $N_{k}^{(\ell+1)}\left(h_{k}\right)$ is empty, there is nothing to prove.) That is, we have for all $\tilde{\ell}$ with $\ell+1 \geq \tilde{\ell} \geq 1, r_{\tilde{I}^{j}}^{I}\left(y^{k}\right) \notin Y_{j}^{(\tilde{\ell}), \tilde{I}^{j}}$ or $\left(r_{I^{j}}^{\tilde{I}^{j}}\right)^{-1}\left(\left(s_{k}\left(h_{k}\right)\right)_{j}\right) \cap Y_{j}^{\left(\ell^{\prime}\right), \tilde{I}^{j}} \neq \emptyset$ for some $\ell^{\prime}>\tilde{\ell}$, or $j$ does not strictly prefer $r_{\tilde{I}^{j}}^{I}\left(y^{k}\right)$ over $r_{\tilde{I}^{j}}^{I}\left(y^{-k}\right)$.

Note that since $j \in N_{k}^{(\ell+1)}\left(h_{k}\right)$ we have by N1 that $j$ strictly prefers $r_{I\left(h_{k}\right)}^{I}\left(y^{k}\right)$ over $r_{I\left(h_{k}\right)}^{I}\left(y^{-k}\right)$. Moreover, by N2 we must have $r_{I\left(h_{k}\right)}^{I}\left(y^{k}\right) \in Y_{j}^{\left(\ell^{\prime \prime}\right), I\left(h_{k}\right)}$ for some $\ell^{\prime \prime}$ with $\ell+1 \geq \ell^{\prime \prime} \geq 1$.

With any belief system $\beta_{k} \in B_{k}^{2 \ell+2}$, candidate $k$ must assign strict positive probability to $(2 \ell+1)$-level prudent rationalizable strategies of candidate $-k$ that reveal information to voter $j \in N^{\prime}$ such that an information set $h_{j}$ of voter $j$ in $T^{\tilde{I}^{j}}$ is reached with $Y^{-k}\left(h_{j}\right) \cap$ $Y_{j}^{(\tilde{\ell}), \tilde{I}^{j}} \neq \emptyset$.

Redefine $\bar{N} \subset N$ such that $N_{k}^{(\ell+1)}\left(h_{k}\right) \subseteq \bar{N}$ and

$$
|\bar{N}|=\left\{\begin{array}{cl}
\left\lceil\frac{1}{2}|N|\right\rceil & \text { if } k=a \text { or (if } k=b \text { and }|N| \text { is odd) } \\
\frac{1}{2}|N|+1 & \text { else (i.e., if } k=b \text { and }|N| \text { is even). }
\end{array}\right.
$$

Partition the set of voters $N$ into $\left\{N_{k}^{(\ell+1)}\left(h_{k}\right) \backslash N^{\prime}, N^{\prime}, \bar{N} \backslash N_{k}^{(\ell+1)}\left(h_{k}\right), N \backslash \bar{N}\right\}$. With any belief system $\beta_{k} \in B_{k}^{2 \ell+2}$, candidate $k$ at $h_{k}$ must assign strict positive probability to first-level prudent rationalizable strategies of voter $j$ such that

$$
\text { if } j \in\left\{\begin{array}{ll}
N_{k}^{(\ell+1)}\left(h_{k}\right) \backslash N^{\prime} & \text { then } j \text { votes for } k \\
N^{\prime} & \text { then } j \text { votes for }-k \\
\bar{N} \backslash N_{k}^{(\ell+1)}\left(h_{k}\right) & \text { then } j \text { votes for } k \\
N \backslash \bar{N} & \text { then } j \text { votes for }-k
\end{array},\right.
$$

which implies that candidate $k$ must assign strictly positive probability to $-k$ winning the election. Yet, candidate $k$ can strictly improve his expected payoff at $h_{k}$ given $\beta_{k}\left(h_{k}\right)$ by replacing $\left(s_{k}\left(h_{k}\right)\right)_{j}$ for $j \in N^{\prime}$ with $\left\{r_{I\left(h_{k}\right)}^{I}\left(y^{k}\right)\right\}$, because at any information set $h_{j}$ of voter $j \in N^{\prime}$ reached by this modified strategy of candidate $k$, any $(2 \ell+1)$-level prudent rationalizable strategy of voters $j \in N^{\prime}$ must ascribe voting for $k$ implying that $k$ wins the election, a contradiction.

Hence, since $Y$ is finite, there is a finite $2 \bar{\ell}$ such that for any $\ell>2 \bar{\ell}$ no strategy is eliminated anymore. Moreover, conditions $\bar{\ell}$ imply that neither candidate can change the election outcome by revealing his policy point in the full-dimensional space at any of his information sets in $T^{I}$. Conversely, since we assumed that there is a majority of voters who strictly prefer to vote for one particular candidate when all voters have 
full awareness of political issues and complete information about the policy points, this candidate must also win in any prudent rationalizable outcome under unawareness and incomplete information.

\section{A.2 Proof of Proposition 2}

The proof is analogous to the proof of Proposition 3 with the following modifications:

- Erase (N3).

- Replace (N4) by

$\left(\mathrm{N} 4^{\prime}\right)$ if $\left|N_{k}^{\ell}\left(h_{k}\right)\right|<|N|$ then there is no $N^{\prime} \subseteq N$ satisfying N1 and N2 in place of $N_{k}^{(\ell)}\left(h_{k}\right)$ and for which $\left|N^{\prime}\right|>\left|N_{k}^{(\ell)}\left(h_{k}\right)\right|$.

- Redefine $\bar{N}:=N_{k}^{(\ell)}\left(h_{k}\right)$ and erasing equations (10) and (11).

- Essentially replace "majority of voters" by "every voter" or "some voter", whatever appropriate, throughout.

- Essentially replace " $k$ wins the election" by " $k$ obtains more votes" and "to $-k$ wins the election" by "that $-k$ obtains votes that $k$ could obtain".

\section{References}

[1] Alesina, A. and Cukierman, A. (1990). The political of ambiguity, Quarterly Journal of Economics 105, 829-850.

[2] Aragonès, E. and Neeman, Z. (2000). Ambiguity in electoral competition, Journal of Theoretical Politics 12, 183-204.

[3] Aragonès, E. and Postlewaite, A. (2007). Ambiguity in election games, Review of Economic Design 7, 233-255.

[4] Battigalli, P. (1997). On rationalizability in extensive games, Journal of Economic Theory 74, 40-61. 
[5] Battigalli, P. (2006). Rationalization in signaling games: Theory and applications, International Game Theory Review 8, 67-93.

[6] Berliant, M. and Konishi, H. (2005). Salience: Agenda choices by competing candidates, Public Choice 125, 129-149.

[7] Brady, D., Han, H., and Pope, J.C. (2007). Primary elections and candidate ideology: Out of step with the primary electorate?, Legislative Studies Quarterly 32, 79-105.

[8] Brams, S.J. (1975). Game theory and politics, New York: Free Press.

[9] Budge, I. and Farlie, D. (1983). Explaining and prediction election: Issue effects and party strategy in twenty-three democracies, Allen and Unwin.

[10] Callander, S. and Wilkie, S. (2007). Lies, damned lies, and political campaigns, Games and Economic Behavior 60, 262-286.

[11] Carney, J. and Dickerson, J.F. (2000). Behind the rhetoric, Time Magazine, October 10.

[12] Colomer, J.H. and Llavador, H. (2012). An agenda-setting model of electoral competition, SERIEs: Journal of the Spanish Economic Association 3, 73-93

[13] Downs, A. (1957). An economic theory of democracy, Harper: New York.

[14] Dubey, P. and Kaneko, M. (1984). Information patterns and Nash equilibria in extensive games: I, Mathematical Social Sciences 8, 111-139.

[15] Farquharson, R. (1969). Theory of voting, New Haven: Yale University Press.

[16] Feddersen, T. and Pesendorfer, W. (1997). Voting behavior and information aggregation in elections with private information, Econometrica 65, 1029-1058.

[17] Feinberg, Y. (2009). Games with unawareness, mimeo.

[18] Filiz-Ozbay, E. (2011). Incorporating unawareness into contract theory, mimeo.

[19] Glazer, A. (1990). The strategy of candidate ambiguity, American Political Science Review $84,237-241$.

[20] Glazer, E., Ponzetto, G.A.M., and Shapiro, J. (2005). Strategic extremism: Why Republicans and Democrats divide on religious values, Quarterly Journal of Economics 120, $1283-1330$.

[21] Grant, S. and Quiggin, J. (2011). Inductive reasoning about unawareness, mimeo. 
[22] Gratton, G. (2011). Pandering, faith, and electoral competition, mimeo.

[23] Green, J. and Hobolt, S. (2008). Owning the issue agenda: Party strategies and vote choice in British elections, Electoral Studies 27, 460-476.

[24] Gretlein, R.J. (1982). Dominance solvable voting schemes: A comment, Econometrica 50, $527-528$.

[25] Grossman, S. (1981). The Informational role of Walrasian and private disclosure about the product quality, Journal of Law and Economics 24, 461-483.

[26] Halpern, J. and Rêgo, L. (2006). Extensive games with possibly unaware players, in: Proc. Fifth International Joint Conference on Autonomous Agents and Multiagent Systems, 744751.

[27] Heidhues, P. and Lagerlöf, J. (2003). Hiding information in electoral competition, Games and Economic Behavior 42, 48-74.

[28] Heifetz, A., Meier, M., and Schipper, B.C. (2011a). Dynamic unawareness and rationalizable behavior, University of California, Davis.

[29] Heifetz, A., Meier, M., and Schipper, B.C. (2011b). Prudent rationalizability in generalized extensive-form games, University of California, Davis.

[30] Hillygus, S. and Shields, T. (2008). The persuadable voter, Princeton University Press.

[31] Howard, P.N. and Kreiss, D. (2009). Political parties \& voter privacy: Australia, Canada, the United Kingdom, and United States in comparative perspective, World Information Access Project Working Paper 2009.1, University of Washington.

[32] Jensen, T. (2009). Projection effects and strategic ambiguity in electoral competition, Public Choice 141, 213-232.

[33] Laslier, J.-F. (2006). Ambiguity in electoral competition, Economics of Governance 7, $195-210$.

[34] Laslier, J.-F. (2005). Party objectives in "divide-a-dollar" electoral competition, in: Austen-Smith, D., and Duggan, J. (eds.), Social choice and strategic decisions, Essays in Honor of Jeff Banks, Springer, 113-130.

[35] Laslier, J.-F. and van der Straeten, K. (2004). Electoral competition under imperfect information, Economic Theory 24, 419446 
[36] Li, J. (2006). Dynamic games with perfect awareness information, mimeo.

[37] Li, S.X., Peitz, M., and Zhao, X.J. (2011). Vertically differentiated duopoly with unaware consumers, mimeo.

[38] Lutz, M. (2009). The social pulpit. Barack Obama's social media toolkit, Edelman - Digital Public Affairs.

[39] McKelvey, R. (1980). Ambiguity in spacial models of policy formation, Public Choice 35, $385-401$.

[40] McKelvey, R. and Ordenshook, P.C. (1987). Elections with limited information: A multidimensional model, Mathematical Social Sciences 14, 77-99.

[41] McKelvey, R. and Ordenshook, P.C. (1985). Elections with limited information: A fulfilled expectations model using contemporaneous poll and endorsement data as information sources, Journal of Economic Theory 36, 55-85.

[42] Meier, M. and Schipper, B.C. (2012). Conditional dominance in games with unawareness, University of California, Davis.

[43] Meirowitz, A. (2005). Informational party primaries and strategic ambiguity, Journal of Theoretical Politics 17, 107-136.

[44] Milgrom, P. (1981). Good news and bad news: Representation theorems and applications, Bell Journal of Economics 12, 380-91.

[45] Milgrom, P and Roberts, J. (1986). Relying on the information of interested parties, Rand Journal of Economics 107, 18-32.

[46] Moulin, H. (1979). Dominance solvable voting schemes, Econometrica 47, 1337-1351.

[47] Okuno-Fujiwara, M., Postlewaite, A., and Suzumura, K. (1990). Strategic information revelation, Review of Economic Studies 57, 25-47.

[48] Ozbay, E. (2007). Unawareness and strategic announcements in games with uncertainty, in: Samet, D. (ed.), Proceedings of the 11th conference on Theoretical Aspects of Rationality and Knowledge, Presses Universitaires de Louvain, 231-238.

[49] Page, B.I. (1976). The theory of political ambiguity, American Political Science Review $70,742-752$.

[50] Pearce, D.G. (1984). Rationalizable strategic behavior and the problem of perfection, Econometrica 52, 1029-1050. 
[51] Petrocik, J. (1996). Issue ownership in presidential elections, with a 1980 Case Study, American Journal of Political Science 40, 825-850.

[52] Shepsle, K.A. (1972). The strategy of ambiguity: Uncertainty and electoral competition, American Political Science Review 66, 555-568.

[53] Shepsle, K.A. (1970). A Note on Zeckhauser's "Majority rule with lotteries on alternatives": The case of the Paradox of Voting, Quartely Journal of Economics 84, 705-709.

[54] Shimoji, M. and Watson, J. (1998). Conditional dominance, rationalizability, and game forms, Journal of Economic Theory 83, 161-195.

[55] Stokes, D. (1963). Spatial models of party competition, American Political Science Review $57,368-377$.

[56] Tynan, D. (2004). GOP voter vault shipped overseas. Massive database holds info on millions of voters, and is used to get people to the polls, PC World, September 24.

[57] van Onselen, P. and Errington, W. (2004). Electoral databases: Big brother or democracy unbound?, Australian Journal of Political Science 39, 349-366.

[58] Wayne, L. (2000). The 2000 campaign: The Internet; Voter Profiles Selling Briskly As Privacy Issues Are Raised, New York Times, September 9.

[59] Wisconsin Advertisement Project (2010). http://wiscadproject.wisc.edu/.

[60] Zeckhauser, R. (1969). Majority rule with lotteries on alternatives, Quarterly Journal of Economics 83, 696-703. 